\title{
The dual effect of ephaptic coupling on cardiac conduction with heterogeneous expression of connexin 43
}

\author{
Ning Wei ${ }^{\mathrm{a}}$, Yoichiro Mori ${ }^{\mathrm{a}}$, Elena G. Tolkacheva ${ }^{\mathrm{b}, *}$ \\ ${ }^{a}$ School of Mathematics, University of Minnesota, Minneapolis, MN 55455 \\ ${ }^{b}$ Department of Biomedical Engineering, University of Minnesota, Minneapolis, MN 55455
}

\begin{abstract}
Decreased and heterogeneous expression of connexin $43(\mathrm{Cx} 43)$ are common features in animal heart failure models. Ephpatic coupling, which relies on the presence of junctional cleft space between the ends of adjacent cells, has been suggested to play a more active role in mediating intercellular electrical communication when gap junctions are reduced. To better understand the interplay of $\mathrm{Cx} 43$ expression and ephaptic coupling on cardiac conduction during heart failure, we performed numerical simulations on our model when $\mathrm{Cx} 43$ expression is reduced and heterogeneous. Under severely reduced $\mathrm{Cx} 43$ expression, we identified three new phenomena in the presence of ephaptic coupling: alternating conduction, in which ephaptic and gap junction-mediated mechanisms alternate; instability of planar fronts; and small amplitude action potential (SAP), which has a smaller potential amplitude than the normal action potential. In the presence of heterogeneous $\mathrm{Cx} 43$ expression, ephaptic coupling can either prevent or promote con-
\end{abstract}

\footnotetext{
${ }^{*}$ Corresponding author

Email address: talkacal@umn.edu (Elena G. Tolkacheva)

${ }^{1}$ Address: 312 Church St. SE, 6-128 Nils Hasselmo Hall, Minneapolis, MN 55455.

${ }^{2}$ Tel.: +16126262719 .
} 
duction block (CB) depending on the $\mathrm{Cx} 43$ knockout (Cx43KO) content. When $\mathrm{Cx} 43 \mathrm{KO}$ content is relatively high, ephaptic coupling reduces the probabilities of CB. However, ephaptic coupling promotes CB when $\mathrm{Cx} 43 \mathrm{KO}$ and wild type cells are mixed in roughly equal proportion, which can be attributed to an increase in current-to-load mismatch.

Keywords: Heterogeneous connexin 43, Bidomain model, Alternating conduction, Small amplitude action potential, Instability of planar fronts, Conduction block.

\section{Introduction}

Cardiac cells communicate electrically to coordinate the muscular contraction of the heart to pump blood. Gap junctions are low-resistance pathways that medi4 ate the electrical impulses between myocytes. Gap junctional coupling is one of the key factors that guarantees the velocity and reliability of cardiac conduction Shaw and Rudy (1997); Vaidya et al. (2001); Beauchamp et al. (2004, 2012).

Ventricular myocytes are connected electrically through gap junction channels 8 formed mainly by connexin $43(\mathrm{Cx} 43)$ and, to a smaller extent, $\mathrm{Cx} 45$ Davis et al.

ity of Cx43 can lead to altered patterns of conduction, re-entrant arrhythmias and sudden death, Danik et al. (2004); Gutstein et al. (2001); Jongsma and Wilders (2000); Kanno and Saffitz (2001); Prudat and Kucera (2014). For example, in Danik et al. (2004), authors investigated susceptibility to arrhythmias in a genetically engineered murine model to express progressively decreasing levels of Cx43. Lethal tachyarrhythmias were initiated if cardiac $\mathrm{Cx} 43$ abundance was decreased in a heterogeneous fashion to $18 \%$ of the control level. In Gutstein et al. 
(2001), authors designed a murine model of heterogeneous gap junction channel expression, which results in conduction defects as well as markedly depressed contractile function. Additionally, in Prudat and Kucera (2014), authors showed that velocity and stability of conduction behave in a nonlinear manner when cardiomyocytes expressing different amounts of $\mathrm{Cx} 43$ are combined. In particular, conduction became very heterogeneous and was susceptible to block in the coculturing of $\mathrm{Cx} 43$ knockout (Cx43KO) and wild type (WT) cells, while block was never observed in monogenotypic preparations.

It is widely accepted that gap junctional coupling is the primary mechanism responsible for electrical communication between cardiac cells Rohr (2004). However, recent experimental observation has raised the question of whether conduction can be sustained in the absence of gap junctions Danik et al. (2004); Yao et al. (2003). For instance, in Yao et al. (2003), intercellular conductance measured by dual whole cell voltage clamp in pairs of adult rat ventricular myocytes with genetic $\mathrm{Cx} 43$ ablation was dramatically reduced from $588 \mathrm{nS}$ to $10 \mathrm{nS}$. However, impulse propagation was reduced by only $50 \%$ in tissue composed of the same cells.

One possible explanation of this intriguing observation is ephaptic coupling, first proposed in Sperelakis and Mann (1977) and futher elaborated in Sperelakis and McConnell (2002). In it, neighboring cells are electrically coupled through a narrow cleft space that is resistively connected to the extracellular space. It is further assumed that $\mathrm{Na}^{+}$channels are preferentially localized to the cleft space, as shown by experiments in Cohen (1996); Maier et al. (2002); Kucera et al. (2002); Sperelakis and McConnell (2002). When an action potential reaches one cell, the $\mathrm{Na}^{+}$current flows into the cell from extracellular bath via the cleft, and the 
potential in the cleft space drops. Once the cleft potential becomes sufficiently negative, it depolarizes the membrane of the adjacent cell to the threshold, and that cell then produces an action potential. Several theoretical studies investigated the possible role of ephaptic coupling in cardiac signal propagation Kucera et al. (2002); Mori et al. (2008); Veeraraghavan et al. (2014b); Hand and Peskin (2010); Copene and Keener (2008). In Kucera et al. (2002); Hand and Peskin (2010), the authors assessed the hypothesis that conduction could be modulated by the preferential localization of $\mathrm{Na}^{+}$channels in the cleft space, which causes a large negative potential in the cleft and influences conduction in two opposite ways, depending on the strength of gap junctional coupling. In particular, for normal and moderately reduced gap junctional coupling, localization of $\mathrm{Na}^{+}$channels to the cleft space forces $\mathrm{Na}^{+}$current to go through the large resistance between cleft and extracellular space, which slowed down the conduction. In contrast, for greatly reduced gap junctional coupling, the negative cleft potential induced by $\mathrm{Na}^{+}$current in the prejunctional membrane lead to a suprathreshold depolarization of the postjunctional membrane, which facilitated and accelerated conduction. In Mori et al. (2008), the authors identified a mode of conduction in which the ephaptic and gap-junction-mediated mechanisms alternate. Authors of Copene and Keener (2008) explored the feasibility of ephaptic mechanism in the absence of gap junctions, which is highly parameter dependent.

Decreased and heterogeneous expression of $\mathrm{Cx} 43$ are common features in animal heart failure models Wang and Gerdes (1999); HUANG et al. (1999); Yoshida et al. (2011). Emerging evidence suggests a more active role for ephaptic coupling in mediating intercellular electrical communication when gap junctions are reduced in a homogeneous maner Yao et al. (2003); Kucera et al. (2002); Hand 
and Peskin (2010); Lin and Keener (2014). However, the interplay between heterogeneous $\mathrm{Cx} 43$ expression and ephaptic coupling on cardiac conduction has not been investigated yet. In this manuscript, we aim to explore the effects of ephaptic coupling on cardiac impulse propagation via numerical simulations when $\mathrm{Cx} 43$ expression is reduced and heterogeneous.

\section{Materials and Methods}

\subsection{Mathematical model}

\subsubsection{Bidomain model with ephaptic coupling}

A two dimensional (2D) bidomain model (Fig. 1A of electrical conduction ¿was modified to incorporate ephaptic coupling Hand and Peskin (2010); Copene and Keener (2008), which relies on the presence of a junctional cleft space between the ends of adjacent cells. Each cell is assumed to be cylindrical in shape with radius $r$ and length $L$. The cells are connected by gap junctions to form an $M \times N$ rectangular lattice. At each lattice point $(i, j)$, we associated intracellular potential $\phi_{i}^{(i, j)}$ and extracellular potential $\phi_{e}^{(i, j)}$. The cleft lies in between cells $(i, j)$ and $(i, j+1)$. We then defined a cleft potential $\phi_{c}^{\left(i, j+\frac{1}{2}\right)}$ at location $\left(i, j+\frac{1}{2}\right)$. We called the space, which lies in the extracellular space and stays adjacent to the cleft, the extracellular-cleft space. The potential in the extracellularcleft space is denoted by $\phi_{e c}^{\left(i, j+\frac{1}{2}\right)}$. Note that Fig. $1 \mathrm{~A}$ shows the lattice view of the model, whereas Fig. 1B shows the connection between lattices. In particular, Fig. $1 \mathrm{~B}$ shows a circuit diagram for two adjacent cells that are ephaptically coupled through a common cleft space in the presence of end-to-end gap junctions $\left(G J_{\mathrm{end}}\right)$, side-to-side gap junctions $\left(G J_{\text {side }}\right)$ and resistive connections between extracellular spaces $\left(R_{e e}\right)$ are not shown here. Cleft space was modelled as a single narrow 
compartment with resistive connections $\left(R_{c}\right)$ to the extracellular space; Resistive connections between extracellular space and the extracellular-cleft space are denoted by $R_{e c}$. Intracellular and extracellular spaces of each cell are separated by the cell side membrane; intracellular and cleft spaces are separated by the cell end membrane. Both side and end membranes allow the free flow of ionic and capacitive currents. Ephaptic coupling is maintained by the active end membranes that are connected by a shared cleft potential. In order to save on computational cost, we treated intracellular and extracellular spaces of each cell to be isopotential.

As can be seen from Fig. 1, four different compartments, namely intracellular, extracellular, cleft, and extracellular-cleft spaces, were modelled separately. Current conservation in each compartment provides the following equations, with parameters listed in Table 1

- Intracellular space $\left(\phi_{i}^{(i, j)} ; 1 \leqslant i \leqslant M, 2 \leqslant j \leqslant N-1\right)$ :

$$
\begin{aligned}
& G J_{\text {end }}\left(\phi_{i}^{(i, j)}-\phi_{i}^{(i, j-1)}\right)+G J_{\text {end }}\left(\phi_{i}^{(i, j)}-\phi_{i}^{(i, j+1)}\right) \\
+ & G J_{\text {side }}\left(\phi_{i}^{(i, j)}-\phi_{i}^{(i-1, j)}\right)+G J_{\text {side }}\left(\phi_{i}^{(i, j)}-\phi_{i}^{(i+1, j)}\right) \\
+ & A_{\text {end }} C_{m} \frac{\partial\left(\phi_{i}^{(i, j)}-\phi_{c}^{\left(i, j-\frac{1}{2}\right)}\right)}{\partial t}+A_{\text {end }} C_{m} \frac{\partial\left(\phi_{i}^{(i, j)}-\phi_{c}^{\left(i, j+\frac{1}{2}\right)}\right)}{\partial t}+I_{\text {end }} \\
+ & A_{\text {side }} C_{m} \frac{\partial\left(\phi_{i}^{(i, j)}-\phi_{e}^{(i, j)}\right)}{\partial t}+I_{\text {side }}=0,
\end{aligned}
$$

where $A_{\text {end }}=\pi r^{2}$ and $A_{\text {side }}=2 \pi r L$ denote the cross-sectional and side areas of a cell, respectively; $G J_{\text {end }}=A_{\text {end }} g_{\text {end }}$ and $G J_{\text {side }}=\frac{A_{\text {side }}}{2} g_{\text {side }}$ denote end-to-end and side-to-side gap junctional conductance, respectively; $\phi_{i}^{(i, j)}, \phi_{i}^{(i, j-1)}$ and $\phi_{i}^{(i, j+1)}$ denote the intracellular potentials of cells $(i, j)$, $(i, j-1)$ and $(i, j+1)$, respectively; $\phi_{i}^{(i-1, j)}$ and $\phi_{i}^{(i+1, j)}$ denote the intracellular potentials of cells $(i-1, j)$ and $(i+1, j)$, respectively; $\phi_{c}^{\left(i, j-\frac{1}{2}\right)}$ and 
$\phi_{c}^{\left(i, j+\frac{1}{2}\right)}$ denote cleft potentials at locations $\left(i, j-\frac{1}{2}\right)$ and $\left(i, j+\frac{1}{2}\right)$, respectively; $C_{m}$ represents the membrane capacitance per area; $I_{\text {end }}$ and $I_{\text {side }}$ denote the outward ionic current of the end and side membranes, respectively; $\phi_{e}^{(i, j)}$ represents the extracellular potential of cell $(i, j)$.

Note that for $j=1$, terms $G J_{\text {end }}\left(\phi_{i}^{(i, j)}-\phi_{i}^{(i, j-1)}\right)$ and $A_{\text {end }} C_{m} \frac{\partial\left(\phi_{i}^{(i, j)}-\phi_{c}^{\left(i, j-\frac{1}{2}\right)}\right)}{\partial t}$ are dropped from Eq. 2.1). Similarly, for $j=N$, terms $G J_{\text {end }}\left(\phi_{i}^{(i, j)}-\right.$ $\left.\phi_{i}^{(i, j+1)}\right)$ and $A_{\mathrm{end}} C_{m} \frac{\partial\left(\phi_{i}^{(i, j)}-\phi_{c}^{\left(i, j+\frac{1}{2}\right)}\right)}{\partial t}$ are dropped from Eq. (2.1). In order to minimize the edge effects, we imposed periodic boundary condition in the $x$ direction (see Fig. 1A): we identified $\phi_{i}^{(i-1, j)}$ with $\phi_{i}^{(M, j)}$ for $i=1$, and we identified $\phi_{i}^{(i+1, j)}$ with $\phi_{i}^{(1, j)}$ for $i=M$.

- Extracellular space $\left(\phi_{e}^{(i, j)} ; 1 \leqslant i \leqslant M, 2 \leqslant j \leqslant N-1\right)$ :

$$
\begin{array}{r}
\frac{\phi_{e}^{(i, j)}-\phi_{e c}^{\left(i, j-\frac{1}{2}\right)}}{R_{e c}}+\frac{\phi_{e}^{(i, j)}-\phi_{e c}^{\left(i, j+\frac{1}{2}\right)}}{R_{e c}} \\
+\frac{\phi_{e}^{(i, j)}-\phi_{e}^{(i-1, j)}}{R_{e e}}+\frac{\phi_{e}^{(i, j)}-\phi_{e}^{(i+1, j)}}{R_{e e}} \\
-A_{\text {side }} C_{m} \frac{\partial\left(\phi_{i}^{(i, j)}-\phi_{e}^{(i, j)}\right)}{\partial t}-I_{\text {side }}=0
\end{array}
$$

where $\phi_{e c}^{\left(i, j-\frac{1}{2}\right)}$ and $\phi_{e c}^{\left(i, j+\frac{1}{2}\right)}$ denotes the extracellular-cleft potentials at location $\left(i, j-\frac{1}{2}\right)$ and $\left(i, j+\frac{1}{2}\right)$, respectively; $R_{e c}$ represents the resistance between extracellular space and the extracellular-cleft space; $\phi_{e}^{(i-1, j)}$ and $\phi_{e}^{(i+1, j)}$ denote the extracellular potentials of cells $(i-1, j)$ and $(i+1, j)$, respectively; $R_{e e}$ represents the resistance between extracellular spaces in the $x$ direction (see Fig. $1 \mathrm{~A}$ ).

Note that for $j=1$, term $\frac{\phi_{e}^{(i, j)}-\phi_{e c}^{\left(i, j-\frac{1}{2}\right)}}{R_{e c}}$ is dropped from Eq. (2.2). Similarly, for $j=N, \frac{\phi_{e}^{(i, j)}-\phi_{e c}^{\left(i, j+\frac{1}{2}\right)}}{R_{e c}}$ is dropped from Eq. 2.2). In order to minimize 
the edge effects, we imposed periodic boundary condition in the $x$ direction (see Fig. 1A): we identified $\phi_{e}^{(i-1, j)}$ with $\phi_{e}^{(M, j)}$ for $i=1$, and we identified $\phi_{e}^{(i+1, j)}$ with $\phi_{e}^{(1, j)}$ for $i=M$.

- Cleft space $\left(\phi_{c}^{\left(i, j+\frac{1}{2}\right)} ; 1 \leqslant i \leqslant M, 1 \leqslant j \leqslant N-1\right)$ :

$$
\begin{aligned}
& -A_{\mathrm{end}} C_{m} \frac{\partial\left(\phi_{i}^{(i, j)}-\phi_{\mathrm{c}}^{\left(i, j+\frac{1}{2}\right)}\right)}{\partial t}-A_{\mathrm{end}} C_{m} \frac{\partial\left(\phi_{i}^{(i, j+1)}-\phi_{\mathrm{c}}^{\left(i, j+\frac{1}{2}\right)}\right)}{\partial t}-I_{\mathrm{end}} \\
& +\frac{\phi_{c}^{\left(i, j+\frac{1}{2}\right)}-\phi_{e c}^{\left(i, j+\frac{1}{2}\right)}}{R_{c}}=0,
\end{aligned}
$$

where $R_{c}$ represents the resistance between cleft and extracellular space.

- Extracellular-cleft space $\left(\phi_{e c}^{\left(i, j+\frac{1}{2}\right)} ; 1 \leqslant i \leqslant M, 1 \leqslant j \leqslant N-1\right)$ :

$$
-\frac{\phi_{e}^{(i, j)}-\phi_{e c}^{\left(i, j+\frac{1}{2}\right)}}{R_{e c}}-\frac{\phi_{e}^{(i, j+1)}-\phi_{e c}^{\left(i, j+\frac{1}{2}\right)}}{R_{e c}}-\frac{\phi_{c}^{\left(i, j+\frac{1}{2}\right)}-\phi_{e c}^{\left(i, j+\frac{1}{2}\right)}}{R_{c}}=0 .
$$

\subsubsection{Modeling Cx43 expression}

Since we aim to study the effect of distribution pattern of Cx43KO and WT cells on conduction features in the presence of ephaptic coupling, we followed Prudat and Kucera (2014) to model heterogeneous Cx43 expression, where genotypes of cells were allocated stochastically according to the predefined $\mathrm{Cx} 43 \mathrm{KO}$ content $(p)$. In other words, under each $p$, we stochastically assigned cell genotypes to be $\mathrm{Cx} 43 \mathrm{KO}$ or WT. Here, $p=0$ implies that the $\mathrm{Cx} 43 \mathrm{KO}$ content is $0 \%$, i.e. all cells are WT. In contrast, $p=1$ implies that $\mathrm{Cx} 43 \mathrm{KO}$ content is $100 \%$, i.e. all cells are knockout.

Conductance of gap junctions was set proportionally to the area of contacts between adjacent cells using proportionality constants $g_{\text {end }}$ and $g_{\text {side }}$ (Table 1 ) for end-to-end and side-to-side contacts, respectively. For connections between 
WT cells, $g_{\text {end }}$ and $g_{\text {side }}$ were scaled by a factor $k_{\mathrm{WT}}$ (Table 1 ). For connections between Cx43KO cells, $g_{\text {end }}$ and $g_{\text {side }}$ were scaled by a factor $k_{\mathrm{Cx} 43 \mathrm{KO}}$ (Table 1).

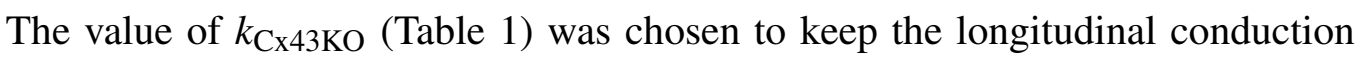
velocity $\left(\mathrm{CV}_{\mathrm{L}}\right)$ in the absence of ephaptic coupling (which can be modelled by a sufficiently large cleft width) the same as $\mathrm{CV}_{\mathrm{L}}$ for $\mathrm{Cx} 43 \mathrm{KO}$ strands reported in Prudat and Kucera (2014), where ephaptic coupling was not considered.

As reported in previous studies, the residual low connexin expressions between $\mathrm{Cx} 43 \mathrm{KO}$ and WT cells are mediated by $\mathrm{Cx} 43 / \mathrm{Cx} 45$ Beauchamp et al. (2012); McCain et al. (2012). For connections between WT and Cx43KO cells, $g_{\text {end }}$ and $g_{\text {side }}$ were also scaled by the factor $k_{\text {Сх43Ко }}$ based on the assumption that the coupling between cells is essentially determined by the cell expressing the least amount of connexins Beauchamp et al. (2012). In Beauchamp et al. (2012), the authors experimentally measures the intercellular conductance between pairs of ventricular myocytes with different $\mathrm{Cx} 43$ expression. They found that ablation of $\mathrm{Cx} 43$ in one cell of a pair caused a marked decrease in mean intercellular conductance, from $68.3 \pm 9.6 \mathrm{nS}$ to $5.2 \pm 1.7 \mathrm{nS}$.

\subsubsection{Membrane currents}

The excitable dynamics of normal cardiac tissue was described by Luo-Rudy dynamic guinea pig ventricular model 2007 (LRd 2007) Livshitz and Rudy (2007). Two different distributions were used for $\mathrm{Na}^{+}$channels: (1) uniform distribution, in which $\mathrm{Na}^{+}$channels are evenly distributed along the cell membrane; (2) localized distribution, in which all $\mathrm{Na}^{+}$channels are localized to the cleft spaces at the two cell ends, while the total conductance of $\mathrm{Na}^{+}$channels is fixed to its normal value. In this study, $\mathrm{Na}^{+}$channels are assumed to be localized to the cleft, unless indicated otherwise. The other ionic channels of LRd 2007 model are uniformly 
distributed along the cell membrane.

Table 1: Parameters that enter our model

\begin{tabular}{|c|c|c|c|c|}
\hline Symbol & Parameter & Value/Expression & \multicolumn{2}{|l|}{ Reference } \\
\hline$r$ & Radius of cell & $1.1 \times 10^{-3} \mathrm{~cm}$ & Hand and Peskin & (2010) \\
\hline$L$ & Length of cell & $10^{-2} \mathrm{~cm}$ & Hand and Peskin $(2$ & (2010) \\
\hline$g_{\text {end }}$ & End-to-end gap junctional & $6.66 \times 10^{2} \mathrm{mS} / \mathrm{cm}^{2}$ & Hand and Peskin $(2$ & (2010) \\
\hline & conductance per area & & & \\
\hline$\alpha$ & Ratio between $g_{\text {end }}$ and $g_{\text {side }}$ & 6 & \multicolumn{2}{|c|}{ Hand et al. (2009) } \\
\hline$g_{\text {side }}$ & $\begin{array}{l}\text { Side-to-side gap junctional } \\
\text { conductance per area }\end{array}$ & $\frac{g_{\text {end }}}{\alpha}$ & \multicolumn{2}{|l|}{ Derived } \\
\hline$C_{m}$ & Membrane capacitance per area & $1 \mu \mathrm{F} / \mathrm{cm}^{2}$ & Hand and Peskin $(2$ & $(2010)$ \\
\hline$d_{\text {cleft }}$ & Cleft width & $2-115 \mathrm{~nm}$ & Hand and Peskin & $(2010)$ \\
\hline$\sigma_{\text {ext }}$ & Extracellular conductivity & $6.67 \mathrm{mS} / \mathrm{cm}$ & Hand and Peskin & $(2010)$ \\
\hline$R_{c}$ & Resistance between cleft & $\frac{1}{8 \pi \sigma_{\text {ext }} d_{\text {cleft }}}$ & Hand and Peskin $(2$ & $(2010)$ \\
\hline & and extracellular space & & & \\
\hline $\mathrm{AR}_{x}$ & Anisotropy ratio of resistance & 1.33 & Keener and Sneyd & $(2010)$ \\
\hline & in $x$ direction & & & \\
\hline $\mathrm{AR}_{y}$ & Anisotropy ratio of resistance & 0.35 & Keener and Sneyd & $(2010)$ \\
\hline & in $y$ direction & & & \\
\hline$R_{e c}$ & Resistance between extracellular space & $\frac{1}{2 \mathrm{AR}_{y} A_{\text {end }} g_{\text {end }}}$ & Keener and Sneyd & (2010) \\
\hline & and extracellular cleft & & & \\
\hline$R_{e e}$ & Resistance between extracellular & $\frac{2}{\mathrm{AR}_{x} A_{\text {side }} g_{\text {side }}}$ & Keener and Sneyd & (2010) \\
\hline & spaces in $x$ direction & & & \\
\hline$k_{\mathrm{WT}}$ & Scaling factor for $g_{\text {end }}$ and $g_{\text {side }}$ between & 1 & Prudat and Kucera & (2014) \\
\hline & WT cells & & & \\
\hline$k_{\mathrm{Cx} 43 \mathrm{KO}}$ & Scaling factor for $g_{\text {end }}$ and $g_{\text {side }}$ between & 0.005 & Derived & \\
\hline & $\mathrm{Cx} 43 \mathrm{KO}$ cells / WT and Cx43KO cells & & & \\
\hline$\phi_{i}$ & Intracellular potential & & & \\
\hline$\phi_{e}$ & Extracellular potential & & & \\
\hline$\phi_{c}$ & Cleft potential & & & \\
\hline$\phi$ & Side transmembrane potential & $\phi_{i}-\phi_{e}$ & & \\
\hline
\end{tabular}




\subsection{Numerical simulation}

Simulations were run in a lattice consisting of $M \times N$ cells (Fig. 1A), where $M=2,3,6,10$, and 16 , and $N=75$. Initially, all potentials and gating variables were held at resting states. Conduction was initiated by applying $0.5 \mathrm{~ms}$ excitatory current pulses of amplitude $0.15 \mu \mathrm{A}$ into all cells at the left hand side of the lattice.

The resulting model consists of a large number of differential algebraic equations. We used a splitting method by updating the potential and gating variables of ion channels separately to solve the system. When updating the potential, gating variables are fixed; the linear parts of the system (linear in potential) were treated using backward Euler method; the ionic currents and dynamics were linearized and treated using backward Euler method afterwards. The system was solved via a direct method (backslash operator in Matlab).

We defined the wavefront of a normal travelling action potential as the spatial location where the side transmembrane potential $(\phi)$ crosses $-30 \mathrm{mV}$ with $\frac{\partial \phi}{\partial t}>0$. This value was set to distinguish small amplitude action potential (SAP) (Sec. 3.2.3 from normal action potential, since SAP does not reach $-30 \mathrm{mV}$. Activation was monitored by identifying the earliest activation time (EAT) at every column of the $M \times N$ lattice (Fig. 1A). $\mathrm{CV}_{\mathrm{L}}$ was computed by linear regression of EAT over $20 \%$ to $80 \%$ of lattice length to exclude the boundary effect. Conduction block (CB) was defined as the failure of wavefront to reach the right hand side of the lattice. 


\section{Results}

\subsection{The effect of ephaptic coupling on cardiac conduction.}

To explore the effects of ephaptic coupling on impulse propagation, we identified several possible values of cleft width $\left(d_{\text {cleft }}\right)$, from $2 \mathrm{~nm}$ to $115 \mathrm{~nm}$ (see Table 11). Note that smaller $d_{\text {cleft }}$ corresponds to larger $R_{c}$, which therefore implies stronger ephaptic coupling.

In Figs. 2A and 2B, $\mathrm{CV}_{\mathrm{L}}$ is plotted as a function of $d_{\text {cleft }}$ for $p=1(\mathrm{~A}, \mathrm{Cx} 43 \mathrm{KO}$ cells) and $p=0$ (B, WT cells), respectively. As observed, Fig. 2A displays a biphasic behavior of $\mathrm{CV}_{\mathrm{L}}$ : with increasing $d_{\text {cleft }}, \mathrm{CV}_{\mathrm{L}}$ exhibits a marked increase to $13.1 \mathrm{~cm} / \mathrm{s}$ (at $d_{\text {cleft }}=8 \mathrm{~nm}$ ) followed by a decrease to $2.5 \mathrm{~cm} / \mathrm{s}$ with further cleft widening. In contrast, when gap junctional coupling is strong, $\mathrm{CV}_{\mathrm{L}}$ shows a monotone increase as $d_{\text {cleft }}$ increases (see Fig. 2B). Note that in Fig. 2, the most notable differences in qualitative behaviors of $\mathrm{CV}_{\mathrm{L}}$ are seen for $d_{\text {cleft }}<20 \mathrm{~nm}$.

To further investigate the effects of ephatic coupling on conduction, we chose $d_{\text {cleft }}=2 \mathrm{~nm}, 3.5 \mathrm{~nm}, 8 \mathrm{~nm}, 8.5 \mathrm{~nm}$, and $115 \mathrm{~nm}$ as the representative values in our numerical simulations.

\subsection{Conduction features when C $x 43 \mathrm{KO}$ content is $100 \%(p=1)$.}

To further explore spatiotemporal excitation patterns that occur in the near absence of gap junctions, we performed numerical simulations in lattices consisting of $100 \% \mathrm{Cx} 43 \mathrm{KO}$ cells. The following three novel conduction features were observed in the presence of ephaptic coupling: alternating conduction (Sec. 3.2.1), instability of planar fronts (Sec. 3.2.2) and SAP (Sec. 3.2.3). However, when gap junction-mediated mechanism dominates ( $d_{\text {cleft }}$ is sufficiently large), none of these features can be observed. Note that alternating conduction and SAP are one- 
dimensional phenomena, which do not depend on lattice width. In contrast, the instability of planar fronts can only be observed in a 2D simulation.

\subsubsection{Alternating conduction}

Fig. 3 shows EAT as a function of $N$ for $d_{\text {cleft }}=8.5 \mathrm{~nm}(\mathrm{~A}), 8.6 \mathrm{~nm}(\mathrm{~B}), 8.7 \mathrm{~nm}$ (C), $8.9 \mathrm{~nm}$ (D), which demonstrates the presence of periodic transitions between fast and slow conduction under severely reduced gap junctions. For instance, at $d_{\text {cleft }}=8.9 \mathrm{~nm}$, action potential propagates fast between columns $N$ and $N+1$ when $N$ is even, but slowly between columns $N$ and $N+1$ when $N$ is odd. Note that for $9 \mathrm{~nm} \leqslant d_{\text {cleft }} \leqslant 9.6 \mathrm{~nm}$, the EAT pattern is the same as that for $d_{\text {cleft }}=$ $8.9 \mathrm{~nm}$.

Fig. 4 shows the end transmembrane potential $\left(\phi_{i c}=\phi_{i}-\phi_{c}\right)$ traces of the left $\left(\phi_{i c \mathrm{~L}}\right)$ and right sides $\left(\phi_{i c \mathrm{R}}\right)$ of cells at location $(3,24),(3,25),(3,26)$ and $(3,27)$, where $d_{\text {cleft }}=5 \mathrm{~nm}(\mathrm{~A}), 8.9 \mathrm{~nm}(\mathrm{~B})$ and $10 \mathrm{~nm}(\mathrm{C})$. As indicated in Fig. 4B, $\phi_{i c}$ traces of the fast conduction phase (cell $(3,24)$ to cell $(3,25)$, and cell $(3,26)$ to cell $(3,27)$ in Fig. 3D are similar to the potential traces $\left(\phi_{i c \mathrm{R}}^{(3,24)}, \phi_{i c \mathrm{~L}}^{(3,25)}, \phi_{i c \mathrm{R}}^{(3,26)}\right.$ and $\phi_{i c \mathrm{~L}}^{(3,27)}$ ) seen when $d_{\text {cleft }}=5 \mathrm{~nm}$, at which the propagation is driven primarily by ephaptic coupling. However, $\phi_{i c}$ profiles of the slow conduction phase (cell $(3,25)$ to cell $(3,26)$ in Fig. $3 \mathrm{D}$ are similar to the potential traces $\left(\phi_{i c \mathrm{R}}^{(3,25)}\right.$ and $\phi_{i c \mathrm{~L}}^{(3,26)}$ ) seen when $d_{\text {cleft }}=10 \mathrm{~nm}$, at which the conduction can be attributed to the residual gap junctional coupling. Alternating conduction shown in Fig. 3 thus lies in an intermediate regime, in which the two aforementioned mechanisms play an equal role, but spatially alternate in being the dominant mode of conduction. Alternating conduction was reported in Mori et al. (2008), where the authors only demonstrated the pattern similar to the one shown in Fig. 3D. However, patterns seen in Figs. 3A- 3Chave never been reported previously. 
Note that two upstrokes are observed in $\phi_{i c \mathrm{R}}^{(3,25)}$ and $\phi_{i c \mathrm{~L}}^{(3,26)}$ traces of Fig. $4 \mathrm{~B}$ and in multiple traces of Fig. $4 \mathrm{C}$. For $\phi_{i c \mathrm{R}}^{(3,25)}$ trace in Fig. $4 \mathrm{~B}$, the first upstroke corresponds to the depolarization of the right end membrane of cell $(3,25)$, which results in a drop in the cleft potential shared by cells $(3,25)$ and $(3,26)$. The drop in the aforementioned cleft potential gives rise to a passive increase in $\phi_{i c \mathrm{~L}}^{(3,26)}$ (first upstroke in $\phi_{i c \mathrm{~L}}(26)$ trace), which is not large enough to activate the left end membrane of cell $(3,26)$. Similarly, the depolarization of left end membrane of cell $(3,26)$ (second upstroke in $\phi_{i c L}^{(3,26)}$ trace) can lead to a passive increase in $\phi_{i c \mathrm{R}}^{(3,25)}$ (second upstroke in $\phi_{i c \mathrm{R}}^{(3,25)}$ trace). Similar explanation can be applied to traces in Fig. 4C. However, in Fig. $4 \mathrm{~A}\left(d_{\text {cleft }}=5 \mathrm{~nm}\right)$, cells are more tightly connected, which gives rise to stronger ephaptic coupling, and therefore, only one upstroke is seen on $\phi_{i c}$ traces.

We point out that the differences in upstroke timing in the $\phi_{i c}$ traces of Fig. 4 are primarily a result of ephaptic coupling (for example $\phi_{i c \mathrm{R}}^{(3,24)}$ and $\phi_{i c \mathrm{~L}}^{(3,25)}$ traces) and different action potential arrival times in the cleft spaces (for example $\phi_{i c L}^{(3,25)}$ and $\phi_{i c \mathrm{R}}^{(3,25)}$ traces). The upstroke timing differences here should thus not be confused with the junctional and intracellular delays discussed in Rohr et al. (1998); Shaw and Rudy (1997), where ephaptic coupling were not considered.

\subsubsection{Instability of planar fronts}

Fig. 5 shows a propagation of an unusual action potential at $d_{\text {cleft }}=9.8 \mathrm{~nm}$, in which instability of planar fronts occurs. This effect is only observed for $9.7 \mathrm{~nm} \leqslant d_{\text {cleft }} \leqslant 9.8 \mathrm{~nm}$. Figs. $5 \mathrm{~A}-5 \mathrm{D}$ show a sequence of snapshots demonstrating propagation when an external current activates all cells at the left hand side of the lattice. The snapshots plot $\phi$ at time $(t)=89 \mathrm{~ms}(\mathrm{~A}), 112 \mathrm{~ms}$ (B), $139 \mathrm{~ms}$ (C) and $173 \mathrm{~ms}$ (D). In order to make the wavefront easier to observe, we 
rotated the figures by $180^{\circ}$. As indicated in Fig. 5 , there is an irregular change in the shape of the wavefront (denoted by black arrows), which proceeds in a zigzag fashion. Such wavefronts propagate to neighboring cells in a spatially heterogeneous manner, rather than evenly along the lattice.

This zigzag wavefront pattern is a result of instability of the planar fronts, reminiscent of stability of front solutions studies in Mori and Matano (2015). Inevitable numerical deviations from the planar front, which will decay and remain small in case of a stable planar front, and grows when the planar front is unstable. Such numerical deviations, in biophysical terms, correspond to external noise; the planar front thus destabilizes in the presence of noise.

We speculate that the instability also results from the presence of two modes of conduction, the ephaptic and the gap junction mediated. Unlike alternating conduction (Sec. 3.2.1) in which the mode of conduction depends only on the $y$ coordinate (Fig. 1A), here, the mode of conduction depends on the $x$-direction as well. A checkerboard pattern of ephaptic and gap junction mediated alternation gives rise to the instability of planar fronts.

\subsubsection{Small amplitude action potentials (SAP)}

Fig. 6 demonstrates a novel type of action potential propagation at $d_{\text {cleft }}=3.5$ $\mathrm{nm}$, which has a much lower potential amplitude than the normal conduction, with the maximum value of $\phi=-40 \mathrm{mV}$. Figs. $6 \mathrm{~A}-6 \mathrm{D}]$ show a sequence of snapshots demonstrating SAP when an external current activates all cells at the left hand side of the lattice. The snapshots illustrate $\phi$ at time $(t)=13 \mathrm{~ms}(\mathrm{~A}), 51 \mathrm{~ms}(\mathrm{~B})$, $80 \mathrm{~ms}(\mathrm{C})$ and $126 \mathrm{~ms}(\mathrm{D})$, respectively.

Note that propagation patterns depend highly on the values of $d_{\text {cleft }}$. For instance, SAP occurs for $3.5 \mathrm{~nm} \leqslant d_{\text {cleft }} \leqslant 3.7 \mathrm{~nm}$, while CB occurs for $3.2 \mathrm{~nm} \leqslant$ 
$d_{\text {cleft }} \leqslant 3.4 \mathrm{~nm}$. For $3.8 \mathrm{~nm} \leqslant d_{\text {cleft }} \leqslant 5 \mathrm{~nm}$, one observes a wave that has characteristics in between normal conduction and SAP (see Fig. 7), reminiscent of stacked fronts observed in lida et al. (2011). Finally, for $2 \mathrm{~nm} \leqslant d_{\text {cleft }} \leqslant 3.1 \mathrm{~nm}$ and $d_{\text {cleft }}>5 \mathrm{~nm}$, normal conduction is seen. However, when $2 \mathrm{~nm} \leqslant d_{\text {cleft }} \leqslant 3.1$ $\mathrm{nm}$, conduction is extremely slow with $\mathrm{CV}_{\mathrm{L}}=0.7 \mathrm{~cm} / \mathrm{s}$.

At $d_{\text {cleft }}=3.5 \mathrm{~nm}, R_{c}$ is very high. In this case, the cleft potential drops low enough to excite the end membrane. However, the resulting inward $\mathrm{Na}^{+}$current is not sufficient to fully activate the side membrane, and therefore SAP occurs. In other words, when SAP occurs, $\mathrm{Na}^{+}$channels residing on the end membrane are fully activated, as indicated by the activation gating variable $\left(m_{\text {end }}\right)$ of $\mathrm{Na}^{+}$ channels that resides on the end membrane of cell $(3,25)$ (Fig. 8A). Nevertheless, the side membrane is not fully excited, as indicated by $\phi$ profile of that cell (Fig. 8B]. SAP may thus be seen as a cardiac propagation jumping from cleft to cleft.

When SAP occurs, L-type $\mathrm{Ca}^{2+}$ channels are not fully activated. Figs. $9 \mathrm{~A}$ and $9 \mathrm{~B}$ show the activation gating variable $(d)$ of $\mathrm{Ca}^{2+}$ channels that reside on the end $\left(d_{\text {end }}, \mathrm{A}\right)$ and side $\left(d_{\text {side }}, \mathrm{B}\right)$ membranes of cell $(3,25)$; Fig. $9 \mathrm{C}$ exhibits $\phi$ profile of cell $(3,25)$, where $d_{\text {cleft }}=3.5 \mathrm{~nm}$ (blue), $3.8 \mathrm{~nm}$ (red), and $115 \mathrm{~nm}$ (green). As observed in Figs. 9A and 9B, gating variable $d$ is not active when SAP occurs $\left(d_{\text {cleft }}=3.5 \mathrm{~nm}\right)$. This is in contrast to normal conduction $\left(d_{\text {cleft }}=115 \mathrm{~nm}\right)$, in which $\mathrm{Ca}^{2+}$ channels are fully activated. SAP is thus a wave in which an electrical pulse propagates without a large rise in $\mathrm{Ca}^{2+}$ concentration. We may therefore regard SAP as an electromechanically dissociated wave.

As shown in Fig. 9, for $d_{\text {cleft }}=3.8 \mathrm{~nm}$, the behaviors of $d_{\text {end }}, d_{\text {side }}$ and $\phi$ lie in an intermediate regime. Unlike SAP, the resulting influx of $\mathrm{Na}^{+}$current is sufficient to activate $\mathrm{Ca}^{2+}$ channels residing on the side membrane, indicated by 
$d_{\text {side }}$ in Fig. 9B. In other words, the steep depolarization of side membrane results from $\mathrm{Na}^{+}$current, whereas the shallow depolarization results from L-type $\mathrm{Ca}^{2+}$ current (Fig. 9C). An intermediate wave thus occurs.

\subsection{Conduction block $(C B)$ in mixed genotype lattices.}

In this section, we aim to investigate the possible impacts of interplay between heterogeneous $\mathrm{Cx} 43$ expression and ephaptic coupling on cardiac propagation, specially looking at the occurrence of $\mathrm{CB}$. We performed numerical simulations in an $M \times N$ lattice with a random distribution of WT and $\mathrm{Cx} 43$ cells according to the predefined $\mathrm{Cx} 43 \mathrm{KO}$ content $(0 \leqslant p \leqslant 1)$, while incorporating different values of $d_{\text {cleft. }}$ As stated in Sec. 2.2, $M=2,3,6,10$ and 16, $N=75$.

For each lattice, numerical simulations were implemented 100 iterations for every $p, d_{\text {cleft }}$ and $\mathrm{Na}^{+}$channel distribution, thus taking into account different realizations of cellular architecture.

\subsubsection{Ephaptic coupling can suppress $C B$ when $p \geqslant 0.7$.}

Tables 2 and 3 show the number of CB observed for different $p$ and $d_{\text {cleft }}$ in $2 \times 75$ and $3 \times 75$ lattices, respectively. Note that there is no CB for monogenotypic preparations ( $p=0$ or 1). However, co-culturing of Cx43KO and WT cells results in increased probabilities of $\mathrm{CB}$, especially for $0.2 \leqslant p \leqslant 0.6$. This is consistent with the results of Prudat and Kucera (2014), where CB was studied without ephaptic coupling (corresponding to $d_{\text {cleft }}=115 \mathrm{~nm}$ in our simulations). Tables 2 and 3 indicate that the proportion of $\mathrm{CB}$ in the above range is independent of the value of $d_{\text {cleft }}$ and thus of ephaptic coupling.

The number of CB in Tables 2 and 3 , however, shows a dependency on $d_{\text {cleft }}$ when $0.7 \leqslant p \leqslant 0.9$. The proportion of CB for $d_{\text {cleft }}=8 \mathrm{~nm}$ is lower than that for 
$d_{\text {cleft }}=115 \mathrm{~nm}$. Indeed, in Table 2 , for $0.7 \leqslant p \leqslant 0.8$, the differences in the number of CB at $d_{\text {cleft }}=8 \mathrm{~nm}$ and $d_{\text {cleft }}=115 \mathrm{~nm}$ are statistically significant according to two-proportion $z$-test ( $z=3.6$ and 2.5 , respectively). For $p=0.9$, statistically significant difference $(z=2.3)$ can be detected if more than 800 numerical experiments are performed (data is not shown in Table 2). In Table 3, for $p=0.7$, we observed statistically significant difference $(z=3.3)$ in the occurrence of CB between $d_{\text {cleft }}=8 \mathrm{~nm}$ and $115 \mathrm{~nm}$. At $p=0.8$, statistically significant difference $(z=4.8)$ can be observed when the number of numerical experiments is increased to 400 (data is not shown in Table 3). Recall that the maximum $\mathrm{CV}_{\mathrm{L}}$ was achieved at $d_{\text {cleft }}=8 \mathrm{~nm}$ (see Fig. 2A) in the near absence of gap junctional coupling; and at $d_{\text {cleft }}=115 \mathrm{~nm}$, propagation is mainly supported by gap junctional coupling (see Section 3.1). When $0.7 \leqslant p \leqslant 0.9$, ephaptic coupling can thus reduce the number of $\mathrm{CB}$, which points to an advantage of ephaptic coupling.

Recall from Sec. 3.2 .3 that SAP occurs at $d_{\text {cleft }}=3.5 \mathrm{~nm}$ when $p=1$. At $p=0.9$ and $d_{\text {cleft }}=3.5 \mathrm{~nm}$ in Tables 2 and 3, SAP is seen when there is no CB.

\subsubsection{Ephaptic coupling can enhance $C B$ when $0.4 \leqslant p \leqslant 0.6$.}

Tables 4- 6 show the number of CB for different $p$ and $d_{\text {cleft }}$ in $6 \times 75,10 \times 75$ and $16 \times 75$ lattices, respectively. Note that CB was never observed in monogenotypic preparations ( $p=0$ or 1 ). Nevertheless, similarly to simulations discussed in the previous section, conduction is susceptible to $\mathrm{CB}$ in preparations with mixed WT and Cx43KO cells, especially for $0.4 \leqslant p \leqslant 0.6$. This is seen for all ephaptic coupling strengths and lattice widths.

It can be seen from Tables 2 - 6 that the number of CB generally decreases as the lattice becomes wider. This is most likely because the presence of a larger number of alternative pathways for propagation in wider lattices permits the wave- 
front to bypass sites of low excitability. Exceptions to this rule are seen when $p=0.9, d_{\text {cleft }}=2 \mathrm{~nm}$ and $3.5 \mathrm{~nm}$. When $d_{\text {cleft }}=2 \mathrm{~nm}$, the number of CB increases in wider lattices. When $d_{\text {cleft }}=3.5 \mathrm{~nm}$, the number of CB displays an irregular dependency on the width of the lattice. The mechanism behind the phenomena is still unclear, but the unexplained variations are statistically significant.

The alleviatory effect of ephaptic coupling on $\mathrm{CB}$ in narrower lattices shown in Tables 2 and 3 (discussed in the previous section) is also present in wider lattices (Tables $4-6,0.7 \leqslant p \leqslant 0.9$ ). The magnitude of this effect, seems to be smaller, however.

A new feature observed in wider lattices but not seen in narrower lattices is that the number of CB shows a dependency on $d_{\text {cleft }}$ when $0.4 \leqslant p \leqslant 0.6$. As seen in Tables 4- 6 the proportion of CB is lower at $d_{\text {cleft }}=115 \mathrm{~nm}$ than at smaller $d_{\text {cleft }}$. This implies that ephaptic coupling does not prevent, but rather, facilitates $\mathrm{CB}$ in this parameter range. Indeed, in Table 6, for $0.4 \leqslant p \leqslant 0.6$, the differences in the number of CB at $d_{\text {cleft }}=115 \mathrm{~nm}$ and smaller $d_{\text {cleft }}$ are statistically significant according to the two-proportion $z$-test. Additionally, in Table 5, when $0.4 \leqslant p \leqslant 0.6$, the statistically significant differences in the occurrence of CB between $d_{\text {cleft }}=115 \mathrm{~nm}$ and $d_{\text {cleft }}=8 \mathrm{~nm}$ or $8.5 \mathrm{~nm}$ can be detected if 400 numerical experiments are performed (data is not shown in Table 5). In Table 4, for $p=0.6$, a statistically significant difference between $d_{\text {cleft }}=115 \mathrm{~nm}$ and $8 \mathrm{~nm}$ can be seen if the number of numerical experiments is increased to 400 (data is not shown in Table 47. Ephaptic coupling can thus increase the possibility of CB in the cocultures, which points to a disadvantage of ephaptic coupling. We see that this effect is more pronounced in wider lattices.

When $p=0.9$, SAP still occurs at $d_{\text {cleft }}=3.5 \mathrm{~nm}$ in Tables 4 and 5 , but the 
number of occurrences of $\mathrm{CB}$ is 2 and 1, respectively.

We have checked that the effect of suppressing (Sec. 3.3.1) or promoting CB (Sec. 3.3.2) is only seen when $\mathrm{Na}^{+}$channels are localized to the cleft; indeed, when $\mathrm{Na}^{+}$channel is uniformly distributed, the number of CB is independent of $d_{\text {cleft }}$ values and is almost the same as the numbers in Tables 2 - 6 for $d_{\text {cleft }}=115$ $\mathrm{nm}$ (data is not shown). This implies that ephaptic coupling does not modulate CB when $\mathrm{Na}^{+}$channel distribution is uniform.

Table 2: Number of CB for a $2 \times 75$ lattice. For $0.7 \leqslant p \leqslant 0.8$, the differences in the number of CB at $d_{\text {cleft }}=8 \mathrm{~nm}$ and $d_{\text {cleft }}=115 \mathrm{~nm}$ are statistically significant according to the two-proportions $z$-test $(z=3.6$ and 2.5 , respectively). For $p=0.9$, statistically significant difference $(z=2.3)$ can be detected if more than 800 numerical experiments are performed (data not shown).

\begin{tabular}{|c|c|c|c|c|c|c|c|c|c|c|c|}
\hline $\begin{array}{c}y \\
d_{\text {cleft }}(\mathrm{nm})\end{array}$ & 0 & 0.1 & 0.2 & 0.3 & 0.4 & 0.5 & 0.6 & 0.7 & 0.8 & 0.9 & 1 \\
\hline 2 & 0 & 93 & 100 & 100 & 100 & 100 & 100 & 100 & 100 & 74 & 0 \\
\hline 3.5 & 0 & 92 & 100 & 100 & 100 & 100 & 100 & 100 & 100 & 78 & SAP \\
\hline 8 & 0 & 92 & 100 & 100 & 100 & 100 & 95 & $\mathbf{5 5}$ & $\mathbf{1 6}$ & $\mathbf{3}$ & 0 \\
\hline 8.5 & 0 & 92 & 100 & 100 & 100 & 100 & 95 & 55 & 18 & 4 & 0 \\
\hline 115 & 0 & 92 & 100 & 100 & 100 & 100 & 99 & 79 & 31 & 5 & 0 \\
\hline
\end{tabular}


Table 3: Number of CB for a $3 \times 75$ lattice. For $p=0.7$, according to the two-proportion $z$-test, we observed statistically significant difference $(z=3.3)$ in the occurrence of CB between $d_{\text {cleft }}=8 \mathrm{~nm}$ and $115 \mathrm{~nm}$. At $p=0.8$, statistically significant difference $(z=4.8)$ can be observed when the number of numerical experiments is increased to 400 (data not shown).

\begin{tabular}{|c|c|c|c|c|c|c|c|c|c|c|c|}
\hline \begin{tabular}{c}
$d_{\text {cleft }}(\mathrm{nm})$ \\
\hline 2
\end{tabular} & 0 & 0.1 & 0.2 & 0.3 & 0.4 & 0.5 & 0.6 & 0.7 & 0.8 & 0.9 & 1 \\
\hline 3.5 & 0 & 48 & 99 & 100 & 100 & 100 & 100 & 100 & 100 & 80 & 0 \\
\hline 8 & 0 & 35 & 94 & 100 & 100 & 100 & 100 & 100 & 100 & 83 & SAP \\
\hline 8.5 & 0 & 35 & 93 & 100 & 100 & 100 & 98 & 46 & 3 & 0 & 0 \\
\hline 115 & 0 & 35 & 93 & 100 & 100 & 100 & 97 & 51 & 5 & 0 & 0 \\
\hline
\end{tabular}

Table 4: Number of CB for a $6 \times 75$ lattice, For $p=0.6$, there are statistically significant differences in the occurrence of CB between $d_{\text {cleft }}=115 \mathrm{~nm}$ and $d_{\text {cleft }}=2 \mathrm{~nm}, 3.5 \mathrm{~nm}$ or $8 \mathrm{~nm}$. In particular, the significant differences between $d_{\text {cleft }}=115 \mathrm{~nm}$ and $d_{\text {cleft }}=8 \mathrm{~nm}$ can be detected if 400 numerical experiments are performed (data not shown).

\begin{tabular}{|c|c|c|c|c|c|c|c|c|c|c|c|}
\hline \begin{tabular}{c}
$d_{\text {cleft }}(\mathrm{nm})$ \\
\hline 2
\end{tabular} & 0 & 0.1 & 0.2 & 0.3 & 0.4 & 0.5 & 0.6 & 0.7 & 0.8 & 0.9 & 1 \\
\hline 3.5 & 0 & 15 & 97 & 100 & 100 & 100 & $\mathbf{1 0 0}$ & 100 & 100 & 79 & 0 \\
\hline 8 & 0 & 0 & 25 & 91 & 100 & 100 & $\mathbf{1 0 0}$ & 100 & 98 & 93 & SAP \\
\hline 8.5 & 0 & 0 & 24 & 88 & 100 & 100 & $\mathbf{8 1}$ & 23 & 1 & 0 & 0 \\
\hline 115 & 0 & 0 & 24 & 88 & 100 & 99 & 74 & 14 & 0 & 0 & 0 \\
\hline
\end{tabular}


Table 5: Number of CB for a $10 \times 75$ lattice. When $0.4 \leqslant p \leqslant 0.6$, there are statistically significant differences in the number of $\mathrm{CB}$ at $d_{\mathrm{cleft}}=115$ and smaller $d_{\mathrm{cleft}}$. In particular, the statistically significant differences between $d_{\text {cleft }}=115 \mathrm{~nm}$ and $d_{\text {cleft }}=8 \mathrm{~nm}$ or $8.5 \mathrm{~nm}$ can be detected if 400 numerical experiments are performed (data not shown).

\begin{tabular}{|c|c|c|c|c|c|c|c|c|c|c|c|}
\hline \begin{tabular}{c}
$d_{\text {cleft }}(\mathrm{nm})$ \\
\hline 2
\end{tabular} & 0 & 0.1 & 0.2 & 0.3 & 0.4 & 0.5 & 0.6 & 0.7 & 0.8 & 0.9 & 1 \\
\hline 3.5 & 0 & 4 & 89 & 100 & $\mathbf{1 0 0}$ & $\mathbf{1 0 0}$ & $\mathbf{1 0 0}$ & 100 & 100 & 92 & 0 \\
\hline 8 & 0 & 0 & 3 & $\mathbf{7 4}$ & $\mathbf{1 0 0}$ & $\mathbf{1 0 0}$ & $\mathbf{1 0 0}$ & 100 & 52 & 54 & SAP \\
\hline 8.5 & 0 & 0 & 1 & 41 & $\mathbf{9 7}$ & $\mathbf{9 9}$ & $\mathbf{6 4}$ & 0 & 0 & 0 & 0 \\
\hline 115 & 0 & 0 & 1 & 40 & $\mathbf{9 6}$ & $\mathbf{9 6}$ & $\mathbf{4 0}$ & 0 & 0 & 0 & 0 \\
\hline
\end{tabular}

Table 6: Number of CB for a $16 \times 75$ lattice. When $0.4 \leqslant p \leqslant 0.6$, the number of CB at $d_{\text {cleft }}=115$ $\mathrm{nm}$ is significantly less than at smaller $d_{\text {cleft }}$.

\begin{tabular}{|c|c|c|c|c|c|c|c|c|c|c|c|}
\hline $\begin{array}{c}y \\
d_{\text {cleft }}(\mathrm{nm})\end{array}$ & 0 & 0.1 & 0.2 & 0.3 & 0.4 & 0.5 & 0.6 & 0.7 & 0.8 & 0.9 & 1 \\
\hline 2 & 0 & 2 & 89 & 100 & $\mathbf{1 0 0}$ & $\mathbf{1 0 0}$ & $\mathbf{1 0 0}$ & 100 & 100 & 99 & 0 \\
\hline 3.5 & 0 & 0 & 1 & 56 & $\mathbf{1 0 0}$ & $\mathbf{1 0 0}$ & $\mathbf{1 0 0}$ & 98 & 37 & 43 & SAP \\
\hline 8 & 0 & 0 & 0 & 12 & $\mathbf{8 3}$ & $\mathbf{9 9}$ & $\mathbf{5 0}$ & 0 & 0 & 0 & 0 \\
\hline 8.5 & 0 & 0 & 0 & 10 & $\mathbf{7 9}$ & $\mathbf{9 7}$ & $\mathbf{2 7}$ & 0 & 0 & 0 & 0 \\
\hline 115 & 0 & 0 & 0 & 7 & $\mathbf{5 9}$ & $\mathbf{5 3}$ & $\mathbf{8}$ & 0 & 0 & 0 & 0 \\
\hline
\end{tabular}

\subsection{Mechanisms behind the increased proportions of $C B$.}

As demonstrated in Sec. 3.3, a smaller $d_{\text {cleft }}$ can either prevent or promote $\mathrm{CB}$ depending on parameter range. In wider lattices, $\mathrm{CB}$ is more frequent in the 
presence of ephaptic coupling when $0.4 \leqslant p \leqslant 0.6$.

We now explore the mechanism behind this observation by using a representative example of $6 \times 75$ lattice at $p=0.6$. A similar analysis can be performed in other cases as well. In Figs. 10- 13, EAT is plotted at different iterations $(i=9,20,35,50$, respectively). In Figs. 10A $11 \mathrm{~A}, 12 \mathrm{~A}$, and $13 \mathrm{~A}$ $d_{\text {cleft }}=2 \mathrm{~nm}, 3.5 \mathrm{~nm}, 8 \mathrm{~nm}$ and $8.5 \mathrm{~nm}$, respectively. In Figs. 10B, 11B, 12B and $13 \mathrm{~B}, d_{\text {cleft }}=115 \mathrm{~nm}$. In each figure, panels $\mathrm{A}$ and $\mathrm{B}$ have the same distribution of $\mathrm{Cx} 43$ expression. We plotted EAT for instances in which CB is seen in the presence of ephaptic coupling $\left(d_{\text {cleft }}=2 \mathrm{~nm}, 3.5 \mathrm{~nm}, 8 \mathrm{~nm}, 8.5 \mathrm{~nm}\right)$ but not in its absence $\left(d_{\text {cleft }}=115 \mathrm{~nm}\right)$. At the location where CB is observed (denoted by $\mathrm{EAT}=0$ ) when ephaptic coupling is present (solid box in panel A), there is always a plateau phase of EAT when ephaptic coupling is absent (solid box in panel B). Similarly, when there is a gap in EAT in the presence of ephaptic coupling (dashed box in panel A), a plateau phase in the EAT is seen in its absence (dashed box in panel B). This implies the presence of relatively large cell clusters that are excited almost simultaneously when ephaptic coupling is absent, but are difficult or impossible to excite when ephaptic coupling is present.

In light of the foregoing, we may describe the mechanism as follows. For $0.4 \leqslant p \leqslant 0.6, \mathrm{Cx} 43 \mathrm{KO}$ and WT cells are mixed in roughly equal proportion. The random distribution of cell genotypes results in local clusters of WT cells coupled through normal levels of gap junctions, which form electric loads that may substantially impair the conduction. When an action potential propagates into such cell clusters, the electric loads can lead to delayed activation or even CB if the activating current is not sufficiently strong.

In the presence of ephaptic coupling (at smaller $d_{\text {cleft }}$ ), $R_{c}$ is high, and the cleft 
potential may drop low enough to excite the end membrane of cell downstream, but the resulting inward current may not be sufficient to excite the entire cell. The high resistance creates a bottleneck that limits the amount of current into the cleft space and across the end membrane of neighboring cell. Ephaptic coupling may thus lead to a decrease in activating current for cells downstream, which together with the increased load discussed above (when $0.4 \leqslant p \leqslant 0.6$ ), may result in a prominent current-to-load mismatch.

\section{Conclusions and Discussions}

In this manuscript, we explored the interplay between reduced heterogeneous Cx43 expression and ephaptic coupling on cardiac action potential propagation. Under severely reduced $\mathrm{Cx} 43$ expression, we identified three new phenomena in the presence of ephaptic coupling: alternating conduction, in which ephaptic and gap junction-mediated mechanisms alternate; instability of planar fronts; and SAP which has a smaller potential amplitude than the normal action potential. We then examined the effects of heterogeneous $\mathrm{Cx} 43$ expression and ephaptic coupling on CB using a 2D cell lattice as our model system. We found that ephaptic coupling can either prevent or promote $\mathrm{CB}$ depending on the $\mathrm{Cx} 43 \mathrm{KO}$ content. When $\mathrm{Cx} 43 \mathrm{KO}$ content is relatively high $(0.7 \leqslant p \leqslant 0.9)$, ephaptic coupling reduces the possibilities of $\mathrm{CB}$, an effect that is greater in narrower lattices. In wider lattices, ephaptic coupling promotes $\mathrm{CB}$ when the $\mathrm{Cx} 43 \mathrm{KO}$ content $0.4 \leqslant p \leqslant 0.6$. This increase in the probabilities of $\mathrm{CB}$ can be attributed to an increase in current-to-load mismatch.

We demonstrated the biphasic behavior of $\mathrm{CV}_{\mathrm{L}}$ as a function of $d_{\text {cleft }}$ when Cx43KO content is $100 \%$ (Sec. 3.1). This nonmonotonicity of $\mathrm{CV}_{\mathrm{L}}$ qualitatively 
agrees with previously published results shown in Kucera et al. (2002); Hand and Peskin (2010). In Kucera et al. (2002), the maximal $\mathrm{CV}_{\mathrm{L}}(15 \mathrm{~cm} / \mathrm{s})$ under $1 \%$ of normal gap junction is achieved at $d_{\text {cleft }}=40 \mathrm{~nm}$. In Hand and Peskin (2010), the maximal $\mathrm{CV}_{\mathrm{L}}(20 \mathrm{~cm} / \mathrm{s})$ is obtained at $d_{\text {cleft }}=11 \mathrm{~nm}$ under $1 \%$ of normal gap junction expression. Although the optimal $d_{\text {cleft }}$ values are quantitatively different from ours, the qualitative behavior of $\mathrm{CV}_{\mathrm{L}}$ is similar.

This is the first study to examine the interaction between heterogeneous $\mathrm{Cx} 43$ expression and ephaptic coupling on the occurrence of $\mathrm{CB}$ (Sec. 3.3). CB, especially unidirectional $\mathrm{CB}(\mathrm{UCB})$ has been considered a substrate for fatal reentrant arrhythmias and sudden cardiac death Waldo and Wit (1993). Therefore, over the last decades, CB or UCB has become the major focus of research. We reported that ephaptic mechanism can lower the possibilities of CB when $\mathrm{Cx} 43 \mathrm{KO}$ content $p \geqslant 0.7$, which implies an anti-arrhythmic role of ephaptic coupling when gap junctions are reduced. This finding is consistent with the result shown in Fig. 2A of Sec. 3.1 and earlier numerical (Mori et al. (2008); Hand and Peskin (2010); Lin and Keener (2014)) and experimental results (Yao et al. (2003); Veeraraghavan et al. (2012)), which suggested that ephaptic coupling can increase conduction speed when gap junction expression is low. On the other hand, we showed that ephaptic coupling can increase the proportion of $\mathrm{CB}$ when $\mathrm{Cx} 43 \mathrm{KO}$ content $0.4 \leqslant p \leqslant 0.6$, which points to a disadvantageous role of ephaptic coupling in this context. This finding is also consistent with the result shown in Fig. 2B of Sec. 3.1. which suggests that ephaptic coupling can reduce conduction velocity when gap junctional coupling is sufficiently high. It is notable that similar results have been reported elsewhere in Kucera et al. (2002); Mori et al. (2008); Hand and Peskin (2010); Lin and Keener (2014). It is important to note, however, that previous 
papers Yao et al. (2003); Mori et al. (2008); Hand and Peskin (2010); Veeraraghavan et al. (2012); Lin and Keener (2014) studied ephaptic coupling by examining its effect on conduction speed with a homogeneous change in gap junctional conductance. Our study focused on the reliability of cardiac signal propagation by studying CB in the presence of heterogeneous Cx43 expression.

Finally, we mention that all the effects of ephaptic coupling mentioned in our findings (results in Sec. 3) are shown to be highly dependent on the localized $\mathrm{Na}^{+}$channels, which are consistent with the experimental and numerical results in Cohen (1996); Maier et al. (2002); Kucera et al. (2002); Sperelakis and McConnell (2002); Hand and Peskin (2010); Veeraraghavan et al. (2014a); Lin and Keener (2014).

In this paper, we adopted a simplified geometry, cell discretization (each cell is treated to be isopotential) and arrangement of cells. We believe that using realistic cell shape or delicate cell arrangement (Prudat and Kucera (2014); Lin and Keener (2014)) will not qualitatively change our conclusions, but may lead to new phenomena. Although we identified some important features of conduction, alternating conduction, instability of planar fronts and SAP, the detailed mechanism behind these phenomena are still unclear. A future study with simplified models may allow us to obtain better understanding. Finally, we mention that the role of Cx43 may not be restricted to electrical conduction, as suggested in Lübkemeier et al. (2013). This is beyond the scope of our current paper, and is a subject for future study. 
4 CONCLUSIONS AND DISCUSSIONS

498

499

500

501

502

503

504

\section{Author Contributions}

N.W., Y.M. and E.G.T. designed research; N.W. performed the research; N.W., Y.M. and E.G.T. analyzed the data; and N.W., Y.M. and E.G.T. wrote the manuscript. All authors approved the final version of the paper.

\section{Acknowledgement}

This work was supported by National Science Foundation [DMS 1516978 to Y.M. and PHY 1255410 and CMMI 1233951 to E.G.T.]. 
505

\section{References}

Beauchamp, P., Choby, C., Desplantez, T., de Peyer, K., Green, K., Yamada, K. A., Weingart, R., Saffitz, J. E., Kléber, A. G., 2004. Electrical propagation in synthetic ventricular myocyte strands from germline connexin 43 knockout mice. Circ. Res. 95 (2), 170-178.

Beauchamp, P., Desplantez, T., McCain, M. L., Li, W., Asimaki, A., Rigoli, G., Parker, K. K., Saffitz, J. E., Kleber, A. G., 2012. Electrical coupling and propagation in engineered ventricular myocardium with heterogeneous expression of connexin43. Circ. Res. 110 (11), 1445-1453.

Cohen, S. A., 1996. Immunocytochemical localization of rh1 sodium channel in adult rat heart atria and ventricle presence in terminal intercalated disks. Circulation 94 (12), 3083-3086.

Copene, E. D., Keener, J. P., 2008. Ephaptic coupling of cardiac cells through the junctional electric potential. J. Math. Biol. 57 (2), 265-284.

Danik, S. B., Liu, F., Zhang, J., Suk, H. J., Morley, G. E., Fishman, G. I., Gutstein, D. E., 2004. Modulation of cardiac gap junction expression and arrhythmic susceptibility. Circ. Res. 95 (10), 1035-1041.

Davis, L. M., Rodefeld, M. E., Green, K., Beyer, E. C., Saffitz, J. E., 1995. Gap junction protein phenotypes of the human heart and conduction system. J. Cardiovasc. Electrophysiol. 6 (10), 813-822.

Gutstein, D. E., Morley, G. E., Vaidya, D., Liu, F., Chen, F. L., Stuhlmann, H., Fishman, G. I., 2001. Heterogeneous expression of gap junction channels in 
the heart leads to conduction defects and ventricular dysfunction. Circulation 104 (10), 1194-1199.

Hand, P. E., Griffith, B. E., Peskin, C. S., 2009. Deriving macroscopic myocardial conductivities by homogenization of microscopic models. Bull. Math. Biol. $71(7), 1707-1726$.

Hand, P. E., Peskin, C. S., 2010. Homogenization of an electrophysiological model for a strand of cardiac myocytes with gap-junctional and electric-field coupling. Bull. Math. Biol. 72 (6), 1408-1424.

HUANG, X.-D., Sandusky, G. E., ZIPES, D. P., 1999. Heterogeneous loss of connexin43 protein in ischemic dog hearts. J. Cardiovasc. Electrophysiol. 10 (1), 79-91.

Iida, M., Lui, R., Ninomiya, H., 2011. Stacked fronts for cooperative systems with equal diffusion coefficients. Siam J. Math. Anal. 43 (3), 1369-1389.

Jongsma, H. J., Wilders, R., 2000. Gap junctions in cardiovascular disease. Circ. Res. 86 (12), 1193-1197.

Kanno, S., Saffitz, J. E., 2001. The role of myocardial gap junctions in electrical conduction and arrhythmogenesis. Cardiovasc. Pathol. 10 (4), 169-177.

Keener, J., Sneyd, J., 2010. Mathematical physiology: I: cellular physiology. Vol. 1. Springer Science \& Business Media.

Kucera, J. P., Rohr, S., Rudy, Y., 2002. Localization of sodium channels in intercalated disks modulates cardiac conduction. Circ. Res 91 (12), 1176-1182. 
Lin, J., Keener, J. P., 2014. Microdomain effects on transverse cardiac propagation. Biophys. J. 106 (4), 925-931.

Livshitz, L. M., Rudy, Y., 2007. Regulation of ca2+ and electrical alternans in cardiac myocytes: role of camkii and repolarizing currents. Am. J. Physiol. Heart Circ. Physiol. 292 (6), H2854-H2866.

Lübkemeier, I., Requardt, R. P., Lin, X., Sasse, P., Andrié, R., Schrickel, J. W., Chkourko, H., Bukauskas, F. F., Kim, J.-S., Frank, M., et al., 2013. Deletion of the last five c-terminal amino acid residues of connexin43 leads to lethal ventricular arrhythmias in mice without affecting coupling via gap junction channels. Basic Res. Cardiol. 108 (3), 1-16.

Maier, S. K., Westenbroek, R. E., Schenkman, K. A., Feigl, E. O., Scheuer, T., Catterall, W. A., 2002. An unexpected role for brain-type sodium channels in coupling of cell surface depolarization to contraction in the heart. Proc. Natl. Acad. Sci. 99 (6), 4073-4078.

McCain, M. L., Desplantez, T., Geisse, N. A., Rothen-Rutishauser, B., Oberer, H., Parker, K. K., Kleber, A. G., 2012. Cell-to-cell coupling in engineered pairs of rat ventricular cardiomyocytes: relation between cx43 immunofluorescence and intercellular electrical conductance. Am. J. Physiol. Heart Circ. Physiol. 302 (2), H443-H450.

Mori, Y., Fishman, G. I., Peskin, C. S., 2008. Ephaptic conduction in a cardiac strand model with 3d electrodiffusion. Proc. Natl. Acad. Sci. 105 (17), 64636468. 
Mori, Y., Matano, H., 2015. Stability of front solutions of the bidomain equation. Comm. Pure Appl. Math. In press.

Prudat, Y., Kucera, J. P., 2014. Nonlinear behaviour of conduction and block in cardiac tissue with heterogeneous expression of connexin 43. J. Mol. Cell. Cardiol. 76, 46-54.

Rohr, S., 2004. Role of gap junctions in the propagation of the cardiac action potential. Cardiovasc. Res. 62 (2), 309-322.

Rohr, S., Kucera, J. P., Kléber, A. G., 1998. Slow conduction in cardiac tissue, i effects of a reduction of excitability versus a reduction of electrical coupling on microconduction. Circ. Res. 83 (8), 781-794.

Shaw, R. M., Rudy, Y., 1997. Ionic mechanisms of propagation in cardiac tissue roles of the sodium and 1-type calcium currents during reduced excitability and decreased gap junction coupling. Circ. Res. 81 (5), 727-741.

Sperelakis, N., Mann, J. E., 1977. Evaluation of electric field changes in the cleft between excitable cells. J. Theor. Biol 64 (1), 71-96.

Sperelakis, N., McConnell, K., 2002. Electric field interactions between closely abutting excitable cells. IEEE Eng. Med. Biol. 21 (1), 77-89.

Vaidya, D., Tamaddon, H. S., Lo, C. W., Taffet, S. M., Delmar, M., Morley, G. E., Jalife, J., 2001. Null mutation of connexin43 causes slow propagation of ventricular activation in the late stages of mouse embryonic development. Circ. Res. 88 (11), 1196-1202. 
Veeraraghavan, R., Lin, J., Hoeker, G. S., Keener, J. P., Gourdie, R. G., Poelzing, S., 2014a. Sodium channels in the cx43 gap junction perinexus may constitute a cardiac ephapse: an experimental and modeling study. Pflügers Arch.-Eur. J. Physiol., 1-13.

Veeraraghavan, R., Poelzing, S., Gourdie, R. G., 2014b. Intercellular electrical communication in the heart: a new, active role for the intercalated disk. Cell communication \& adhesion 21 (3), 161-167.

Veeraraghavan, R., Salama, M. E., Poelzing, S., 2012. Interstitial volume modulates the conduction velocity-gap junction relationship. Am. J. Physiol. Heart Circ. Physiol. 302 (1), H278-H286.

Waldo, A., Wit, A., 1993. Mechanisms of cardiac arrhythmias. The Lancet 341 (8854), 1189-1193.

Wang, X., Gerdes, A. M., 1999. Chronic pressure overload cardiac hypertrophy and failure in guinea pigs: Iii. intercalated disc remodeling. J. Mol. Cell. Cardiol. 31 (2), 333-343.

Yao, J.-A., Gutstein, D. E., Liu, F., Fishman, G. I., Wit, A. L., 2003. Cell coupling between ventricular myocyte pairs from connexin43-deficient murine hearts. Circ. Res. 93 (8), 736-743.

Yoshida, M., Ohkusa, T., Nakashima, T., Takanari, H., Yano, M., Takemura, G., Honjo, H., Kodama, I., Mizukami, Y., Matsuzaki, M., 2011. Alterations in adhesion junction precede gap junction remodelling during the development of heart failure in cardiomyopathic hamsters. Cardiovasc. Res. 92 (1), 95-105. 


\section{Figure captions}

Fig. 1. A lattice view of a 2D bidomain model in the presence of ephaptic coupling (A) and circuit diagram for two adjacent cells coupled through a shared cleft in the presence of end-to-end gap junctions $\left(G J_{\text {end }}\right)(\mathrm{B})$, side-to-side gap junctions $\left(G J_{\text {side }}\right)$ and resistive connections between extracellular spaces $\left(R_{e e}\right)$ are not shown here. This diagram is not to scale, as the cleft width is three orders of magnitude smaller than the length of cell. $\phi_{i}^{(i, j)}$ and $\phi_{i}^{(i, j+1)}$ represent intracellular potentials of cells at location $(i, j)$ and $(i, j+1)$, respectively. $\phi_{e}^{(i, j)}$ and $\phi_{e}^{(i, j+1)}$ represent extracellular potentials of cells $(i, j)$ and $(i, j+1)$, respectively. Cleft space was modelled as a narrow compartment between cells $(i, j)$ and $(i, j+1)$, which is resistively connected $\left(R_{c}\right)$ to the extracellular space. Cleft potential $\phi_{c}^{\left(i, j+\frac{1}{2}\right)}$ is defined at location $\left(i, j+\frac{1}{2}\right)$. The space, which lies in the extracellular space and stays adjacent to the aforementioned cleft is called the extracellular-cleft space. The potential in the extracellular-cleft space is denoted by $\phi_{e c}^{\left(i, j+\frac{1}{2}\right)}$. Resistive connections between extracellular space and the extracellular-cleft space are denoted by $R_{e c}$.

Fig. 2. $\mathrm{CV}_{\mathrm{L}}$ as a function of $d_{\text {cleft }}$ for $p=1(\mathrm{~A}, \mathrm{Cx} 43 \mathrm{KO})$ and $p=0(\mathrm{~B}, \mathrm{WT})$. Fig. 3. EAT as a function of $N$ at $d_{\text {cleft }}=8.5 \mathrm{~nm}(\mathrm{~A}), 8.6 \mathrm{~nm}(\mathrm{~B}), 8.7 \mathrm{~nm}(\mathrm{C})$, $8.9 \mathrm{~nm}(\mathrm{D})$.

Fig. 4. End transmembrane potential $\left(\phi_{i c}=\phi_{i}-\phi_{c}\right)$ traces of the left $\left(\phi_{i c \mathrm{~L}}\right)$ and right $\left(\phi_{i c R}\right)$ sides of cells at location $(3,24),(3,25),(3,26)$ and $(3,27)$, where $d_{\text {cleft }}=5 \mathrm{~nm}(\mathrm{~A}), 8.9 \mathrm{~nm}(\mathrm{~B})$ and $10 \mathrm{~nm}(\mathrm{C})$.

Fig. 5. Instability of planar fronts. A sequence of snapshots of propagation, illustrating $\phi$ at $t=89 \mathrm{~ms}$ (A), $112 \mathrm{~ms}$ (B), $139 \mathrm{~ms}$ (C) and $173 \mathrm{~ms}$ (D), respectively at $d_{\text {cleft }}=9.8 \mathrm{~nm}$. 
Fig. 65: SAP. A sequence of snapshots illustrate $\phi$ at $t=13 \mathrm{~ms}$ (A), $51 \mathrm{~ms}$ (B), $80 \mathrm{~ms}$ (C) and $126 \mathrm{~ms} \mathrm{(D),} \mathrm{respectively} \mathrm{for} d_{\text {cleft }}=3.5 \mathrm{~nm}$.

Fig. 77 Intermediate wave. A sequence of snapshots illustrate $\phi$ at $t=13 \mathrm{~ms}$ (A), $54 \mathrm{~ms}(\mathrm{~B}), 77 \mathrm{~ms}(\mathrm{C})$ and $107 \mathrm{~ms}$ (D), respectively for $d_{\text {cleft }}=3.8 \mathrm{~nm}$.

Fig. 8: Activation gating variable $(m)$ profile of $\mathrm{Na}^{+}$channels residing on the end membrane (A) and $\phi$ profile (B) of cell $(3,25)$ at $d_{\text {cleft }}=3.5 \mathrm{~nm}$.

Fig. 9. Activation gating variable $(d)$ profile of $\mathrm{L}$-type $\mathrm{Ca}^{2+}$ channels residing on the end (A), side (B) membranes and $\phi$ profile $(\mathrm{C})$ of cell $(3,25)$, where $d_{\text {cleft }}=$ $3.5 \mathrm{~nm}$ (blue), $3.8 \mathrm{~nm}$ (red), and $115 \mathrm{~nm}$ (green).

Fig. 10. Representative plots of EAT along a $6 \times 75$ lattice at the $9^{\text {th }}$ iteration, where $p=0.6, d_{\text {cleft }}=2 \mathrm{~nm}(\mathrm{~A}), 115 \mathrm{~nm}$ (B). Conduction delays and CB (A) are denoted by dashed and solid boxes, respectively. Plateau phase of EAT (B) corresponding to conduction delays and CB are denoted by dash and solid boxes, respectively.

Fig. 11 Representative plots of EAT along a $6 \times 75$ lattice at the $20^{\text {th }}$ iteration, where $p=0.6, d_{\text {cleft }}=3.5 \mathrm{~nm}(\mathrm{~A}), 115 \mathrm{~nm}(\mathrm{~B})$. Conduction delays and CB (A) are denoted by dashed and solid boxes, respectively. Plateau phase of EAT (B) corresponding to conduction delays and CB are denoted by dash and solid boxes, respectively.

Fig. 12. Representative plots of EAT along a $6 \times 75$ lattice at the $35^{\text {th }}$ iteration, where $p=0.6, d_{\text {cleft }}=8 \mathrm{~nm}(\mathrm{~A}), 115 \mathrm{~nm}(\mathrm{~B})$. Conduction delays and CB (A) are denoted by dashed and solid boxes, respectively. Plateau phase of EAT (B) corresponding to conduction delays and CB are denoted by dash and solid boxes, respectively.

Fig. 13. Representative plots of EAT along a $6 \times 75$ lattice at the $50^{\text {th }}$ iteration, 
663 where $p=0.6, d_{\text {cleft }}=8.5 \mathrm{~nm}(\mathrm{~A}), 115 \mathrm{~nm}(\mathrm{~B})$. Conduction delays and CB (A) 664 are denoted by dashed and solid boxes, respectively. Plateau phase of EAT (B) 665 corresponding to conduction delays and CB are denoted by dash and solid boxes, 666 respectively. 


\section{Figures}

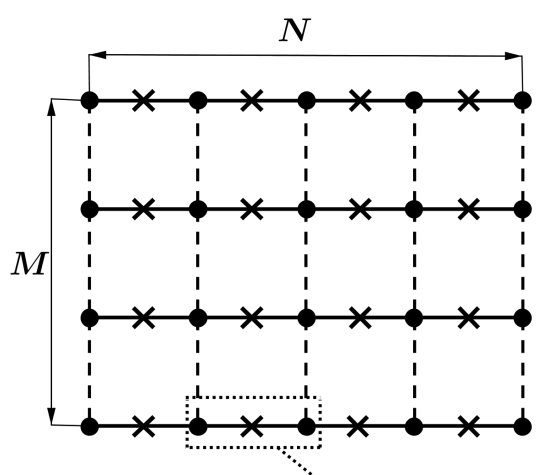

Intracellular lattice
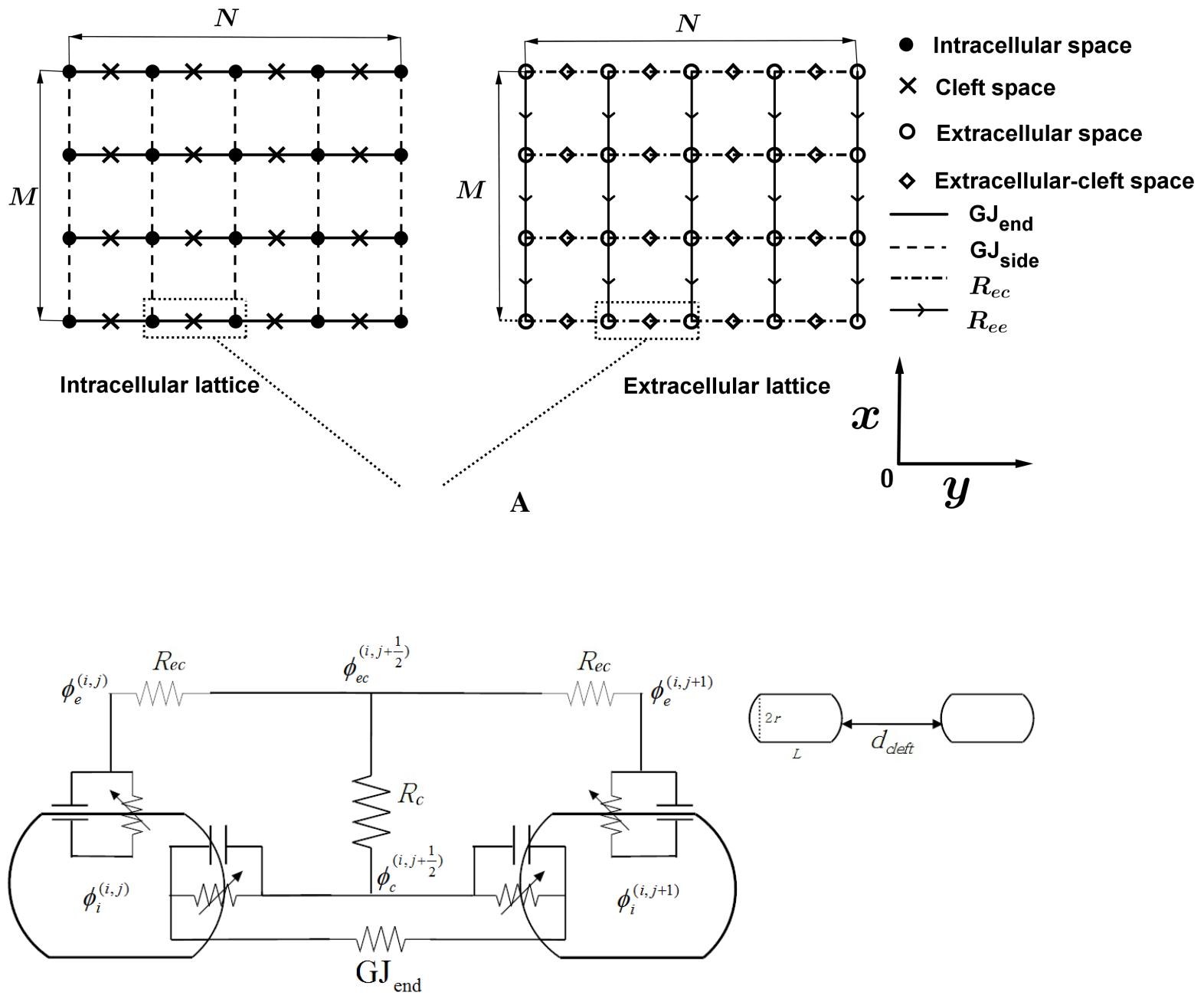

B

Figure 1 


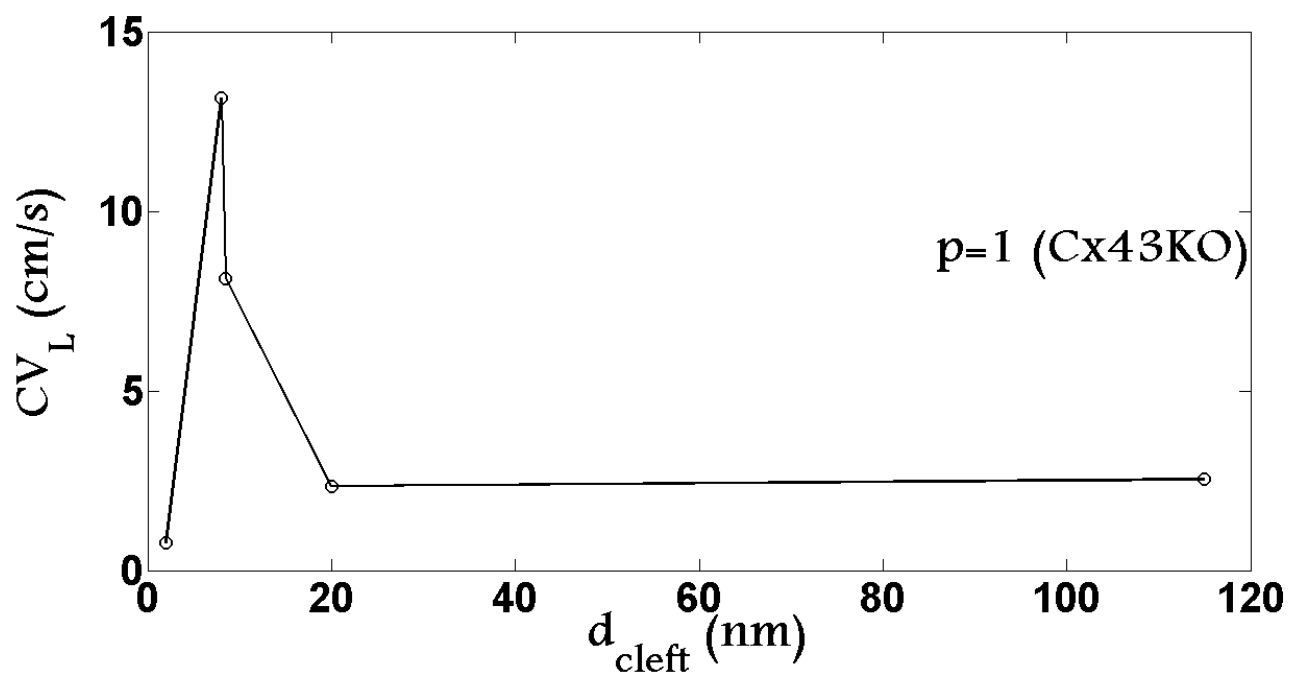

A

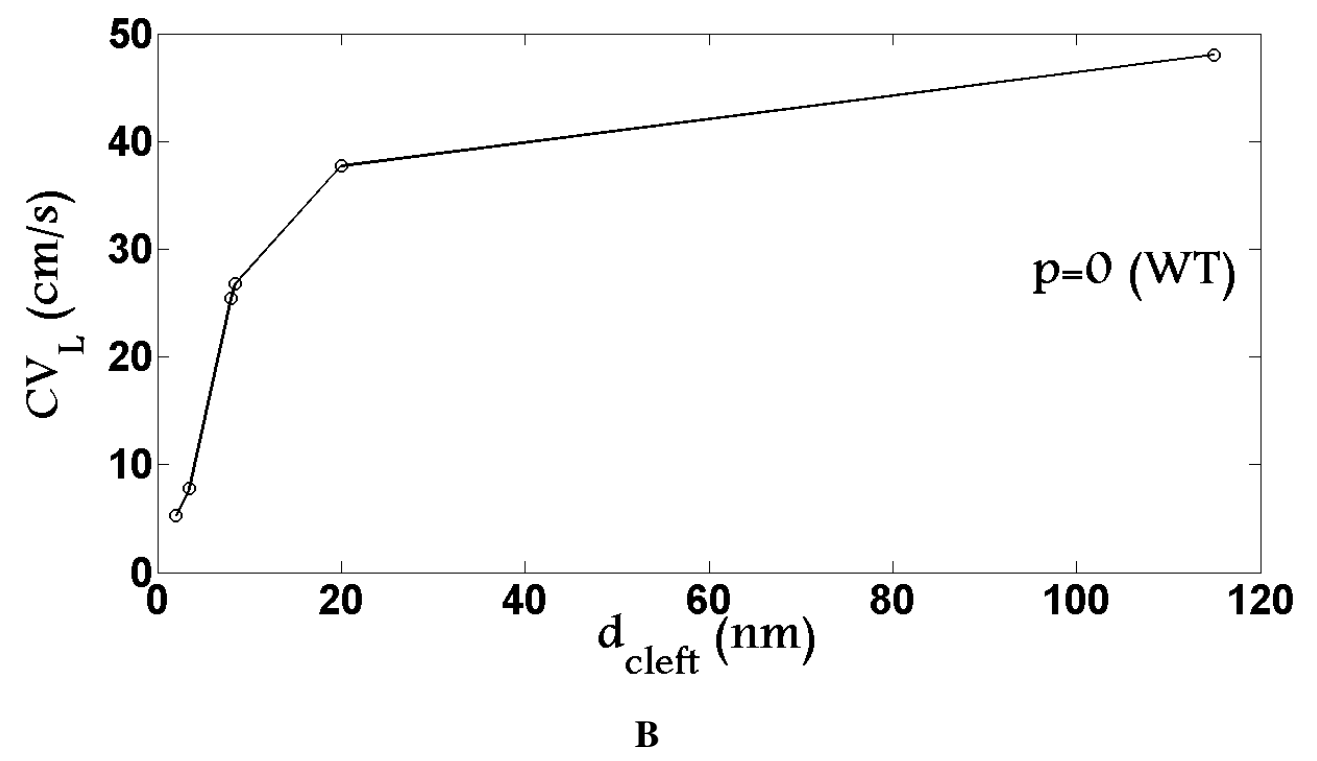

Figure 2 


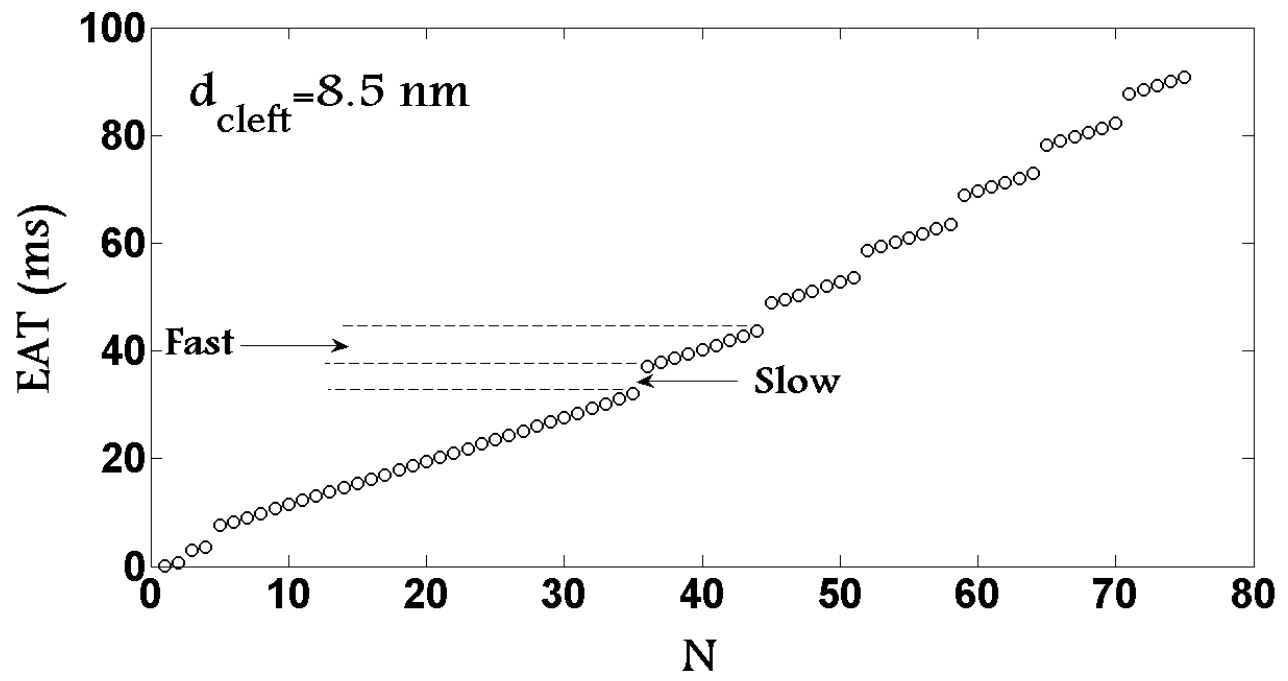

A

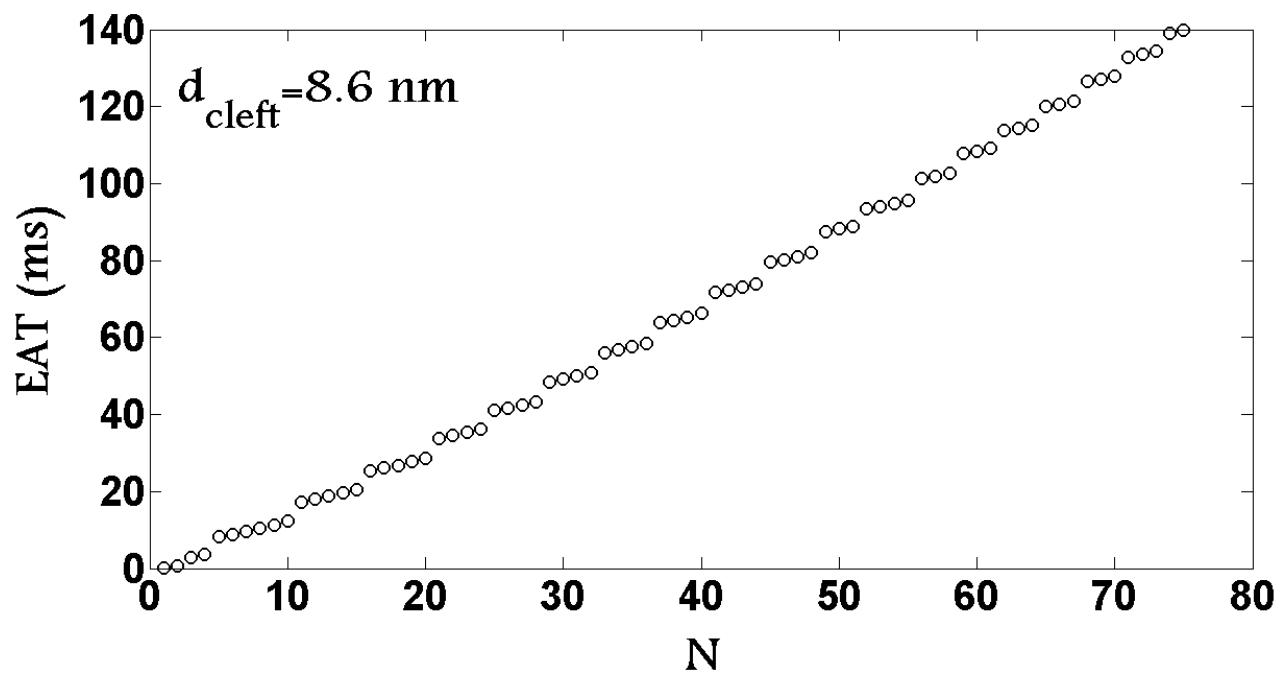

B 


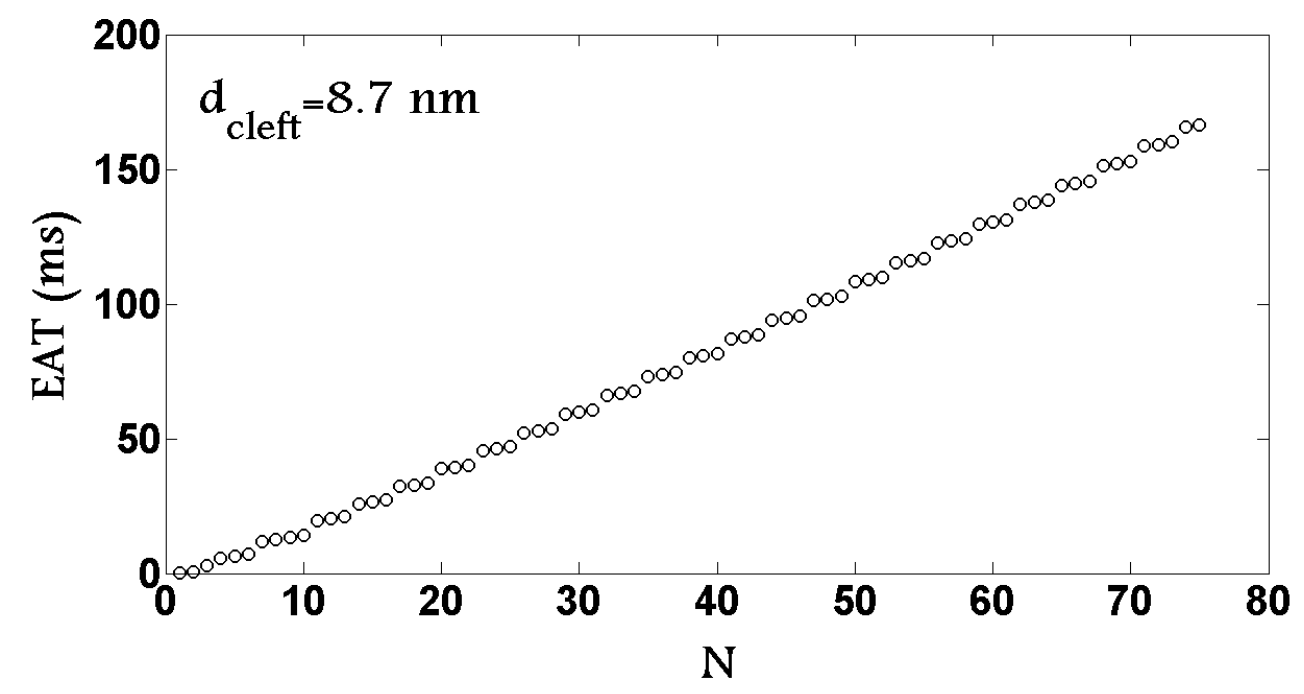

C

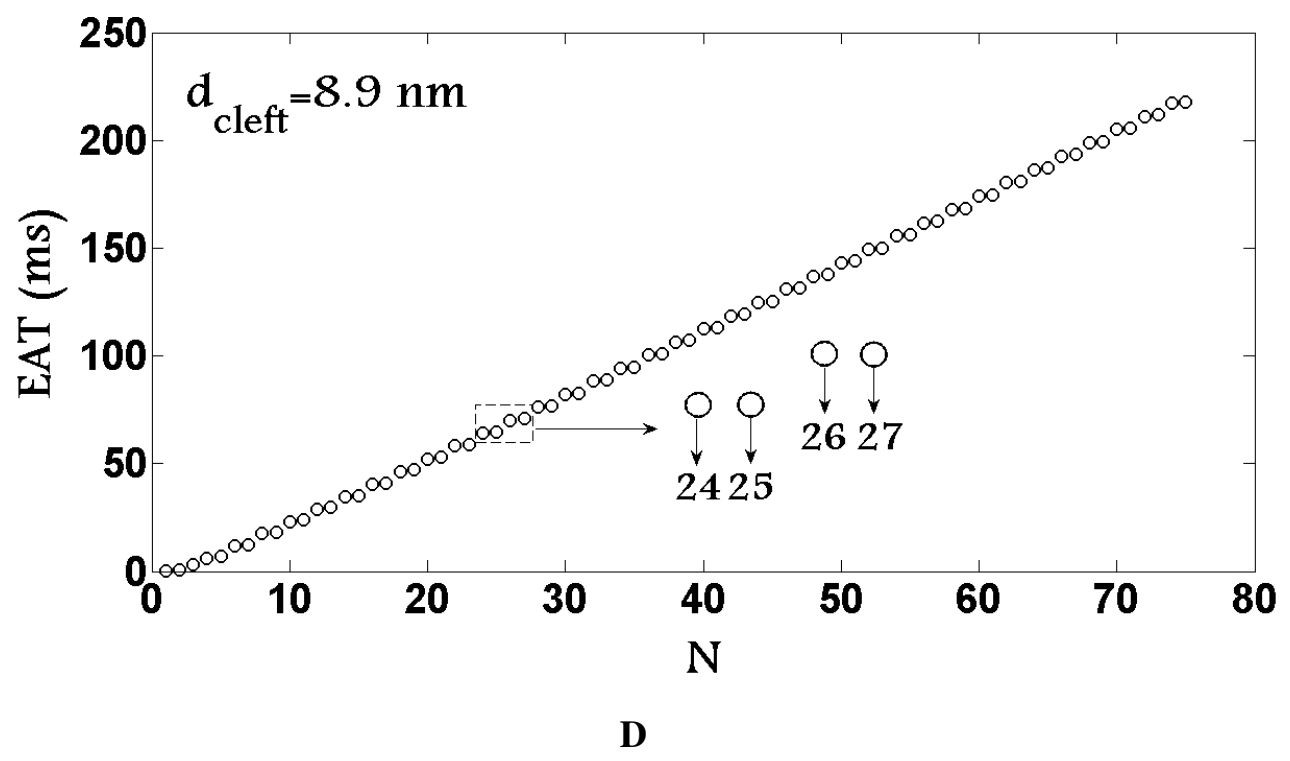

Figure 3 


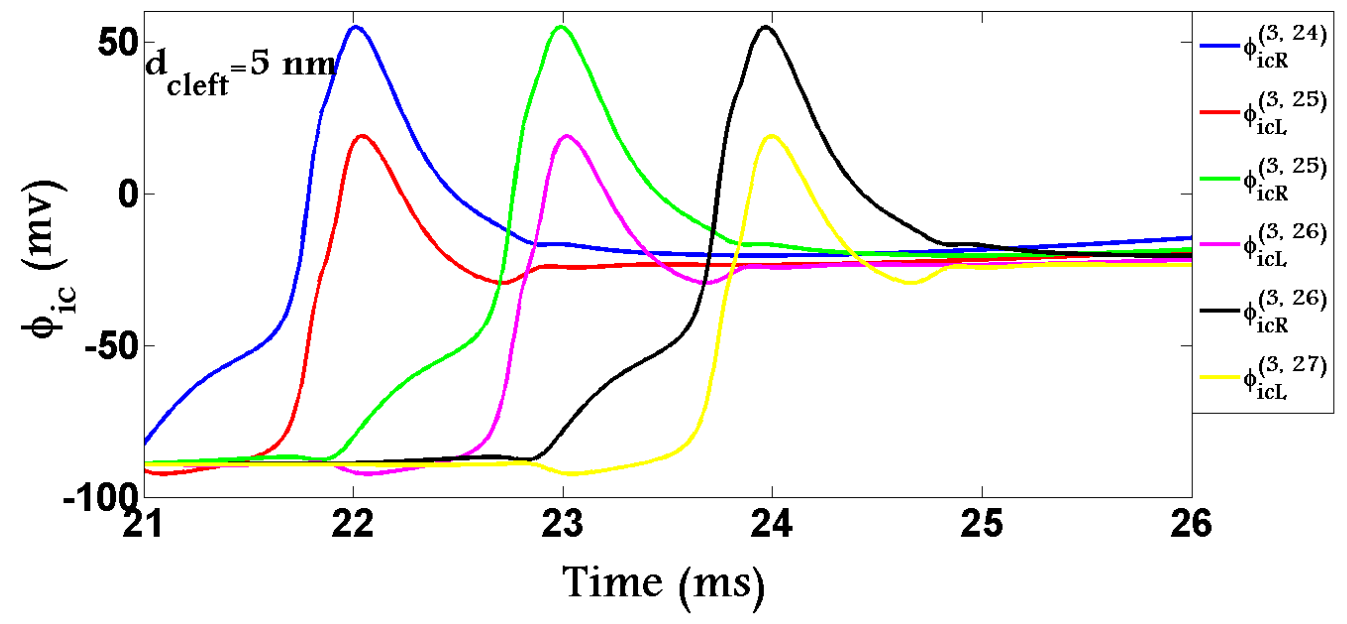

A

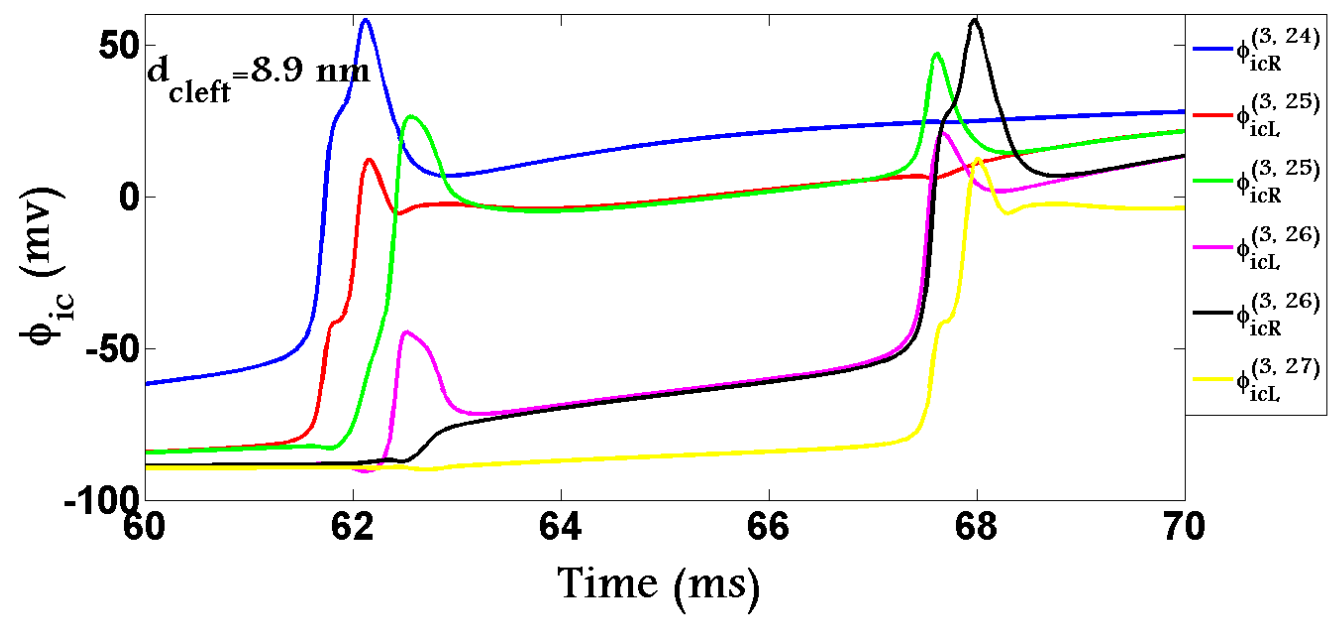

B

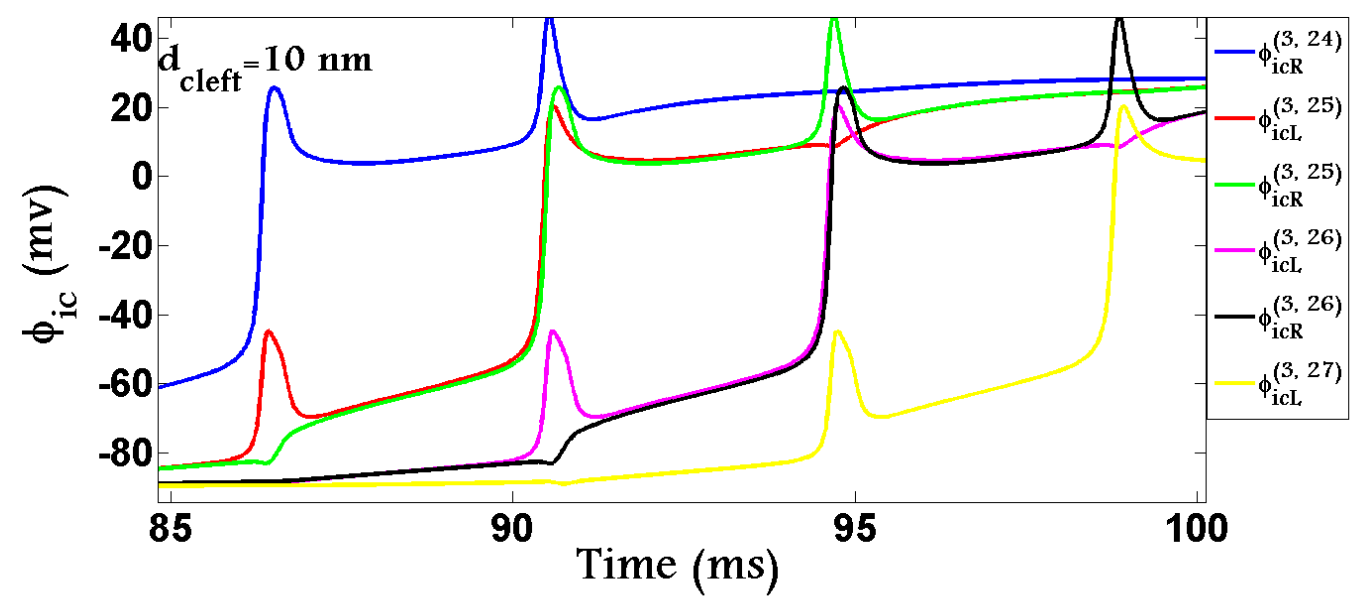

C

Figure 4 


\section{FIGURES}

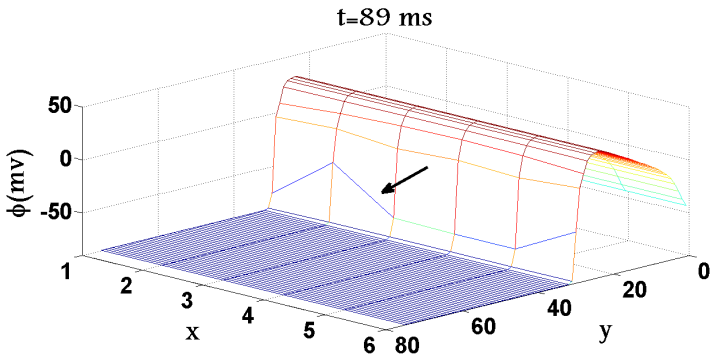

A

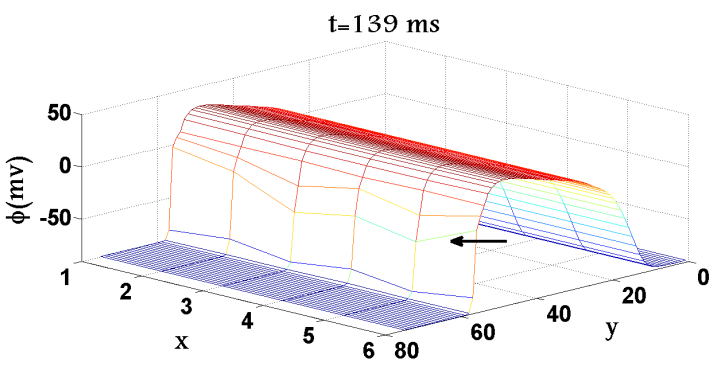

C
41

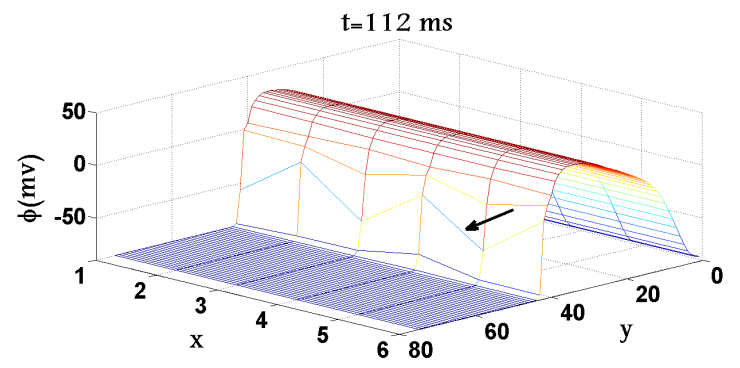

B

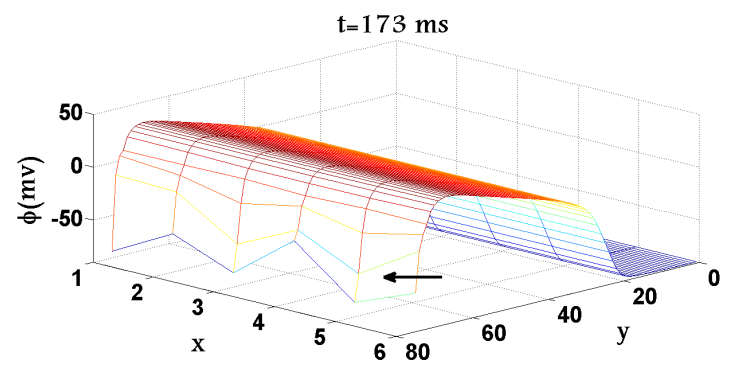

D

Figure 5 


\section{FIGURES}

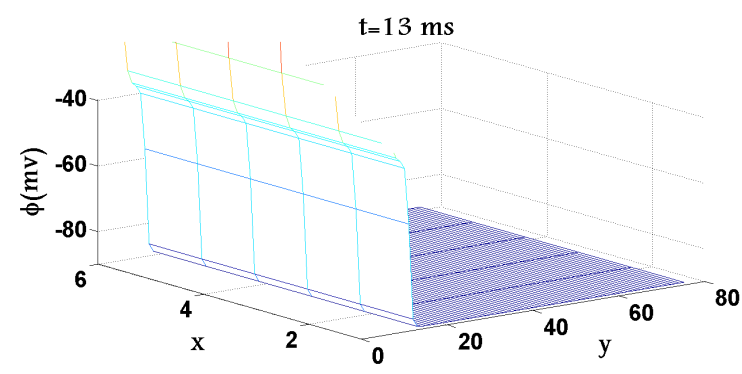

A

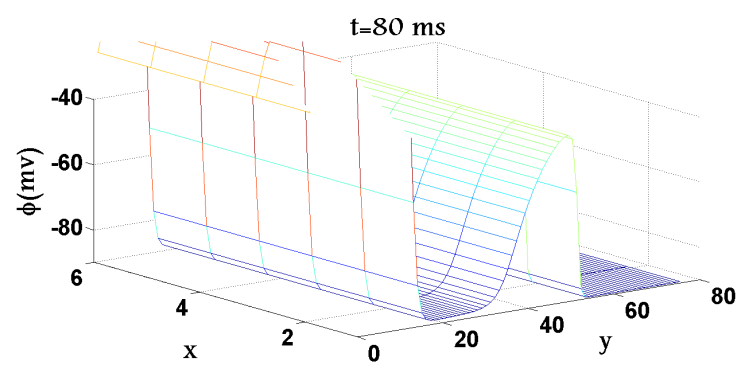

C
42

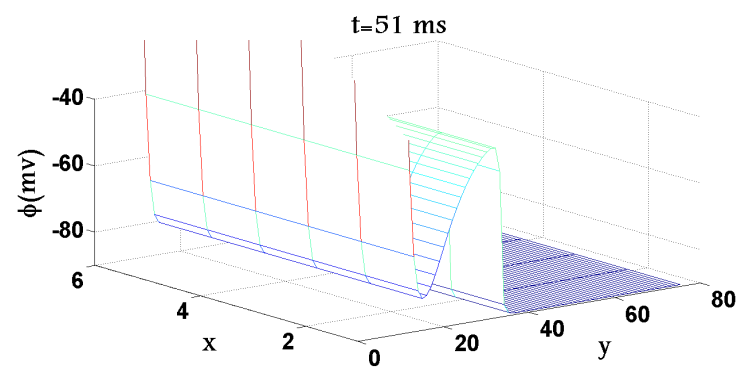

B

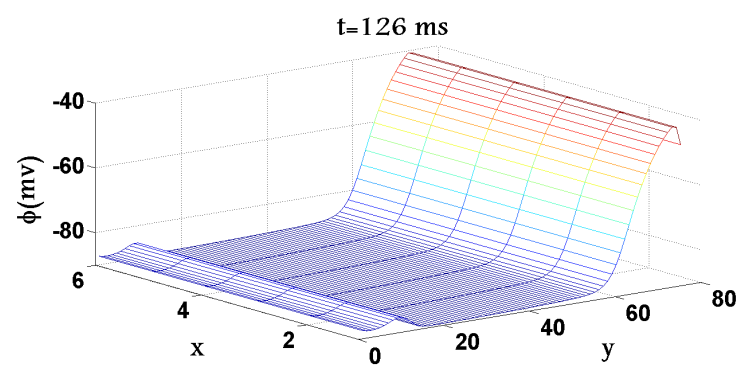

D

Figure 6 


\section{FIGURES}

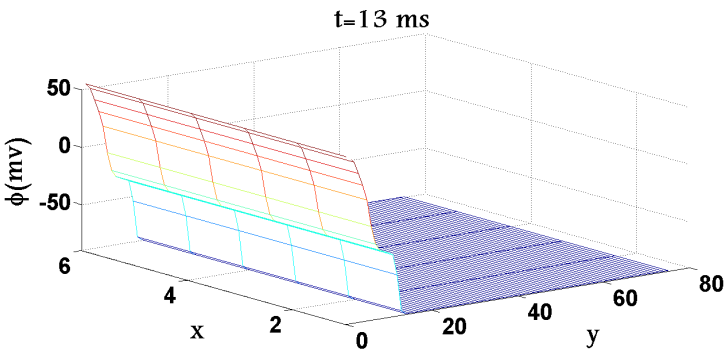

A

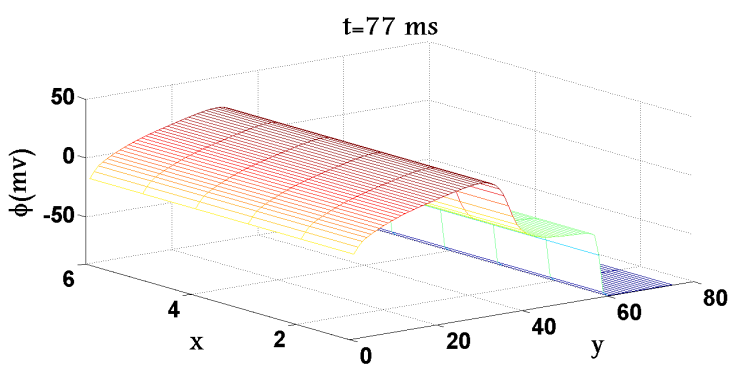

C
43

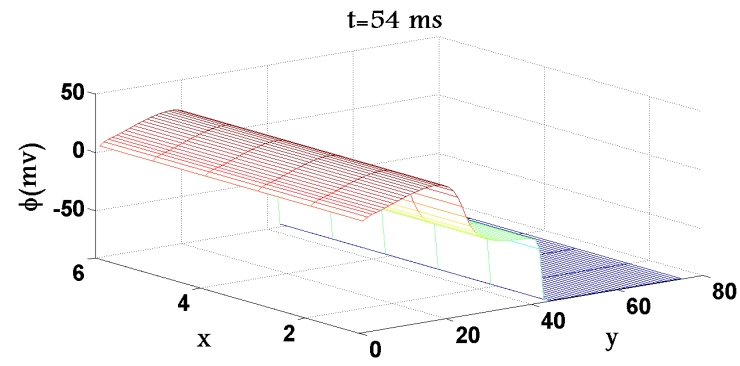

B

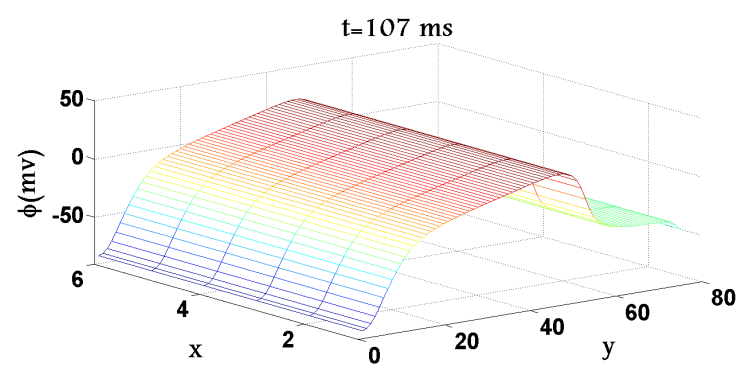

D

Figure 7 

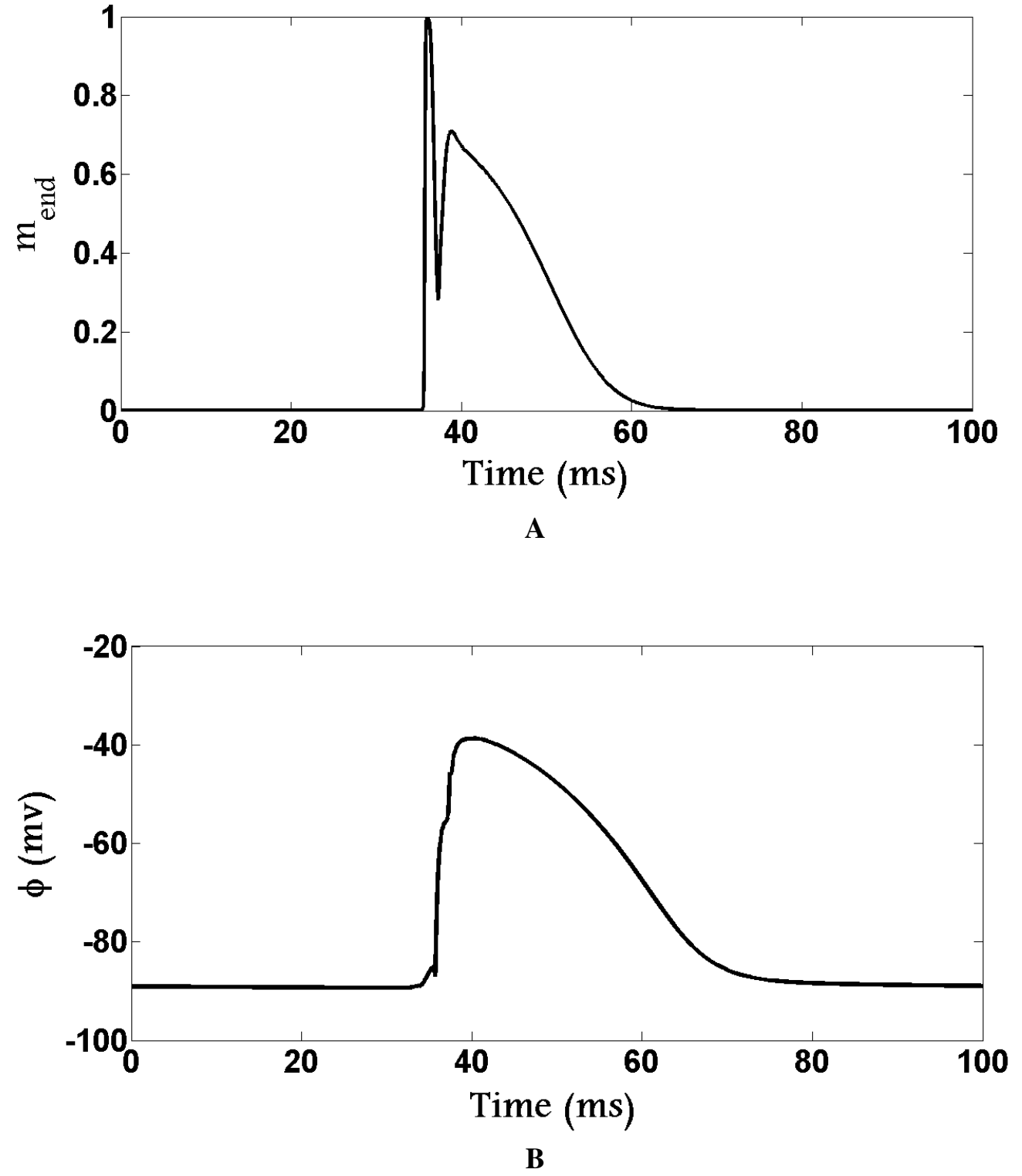

Figure 8 


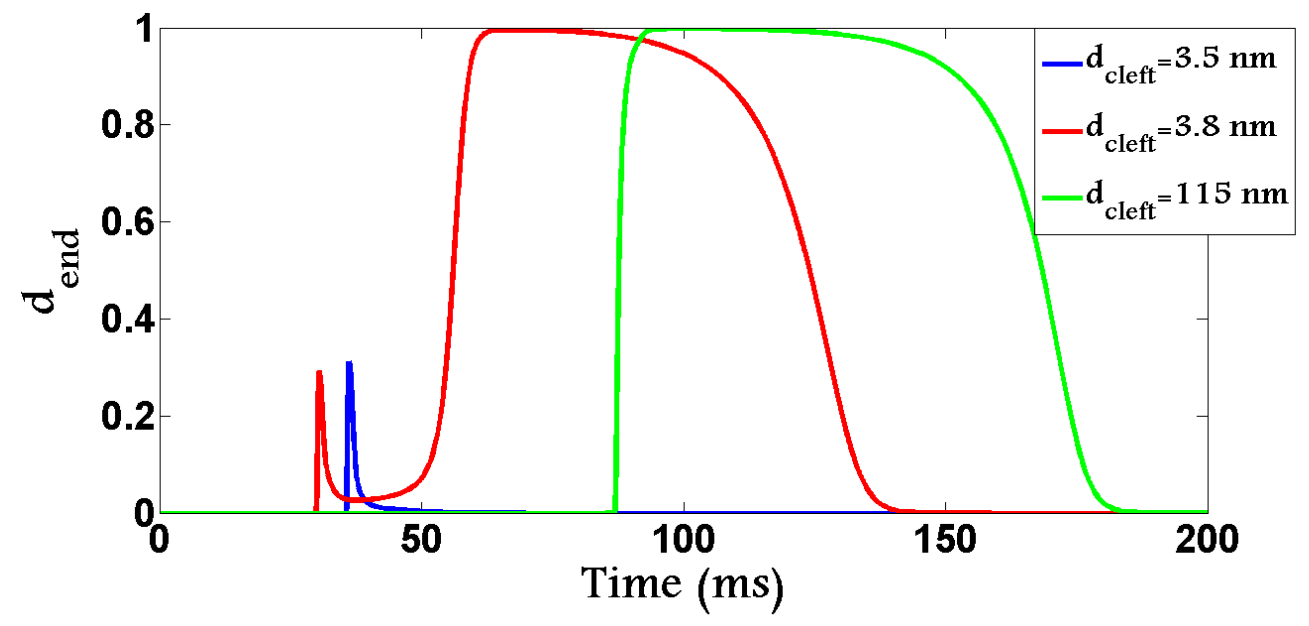

A

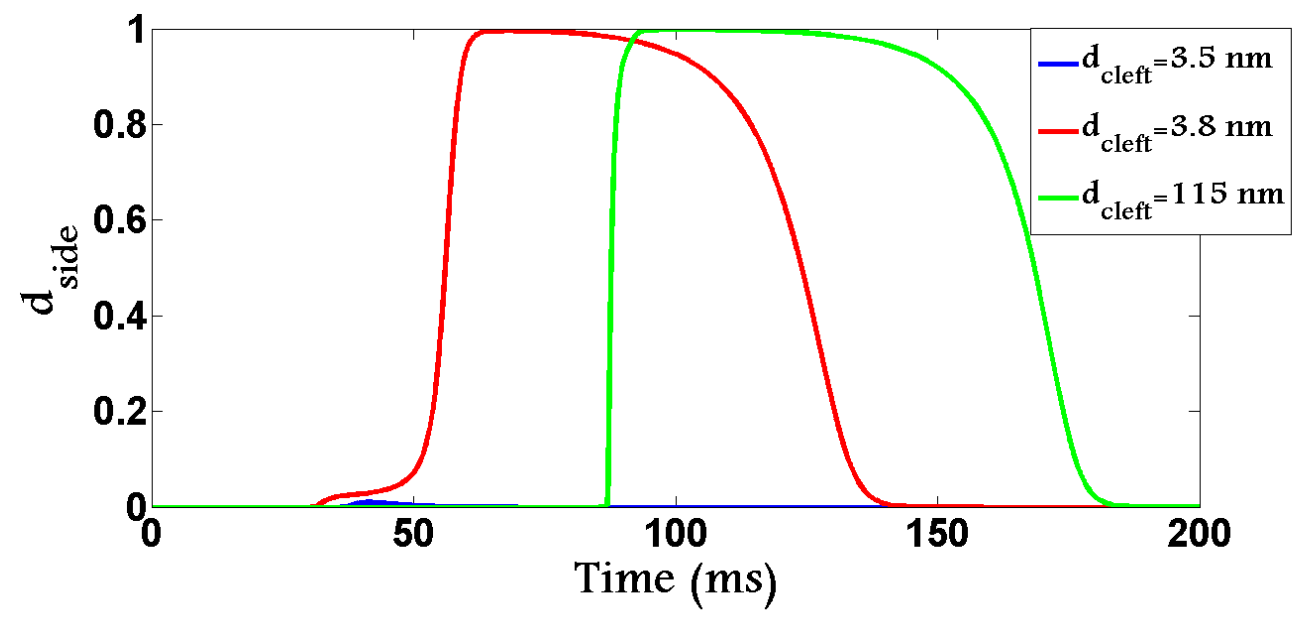

B

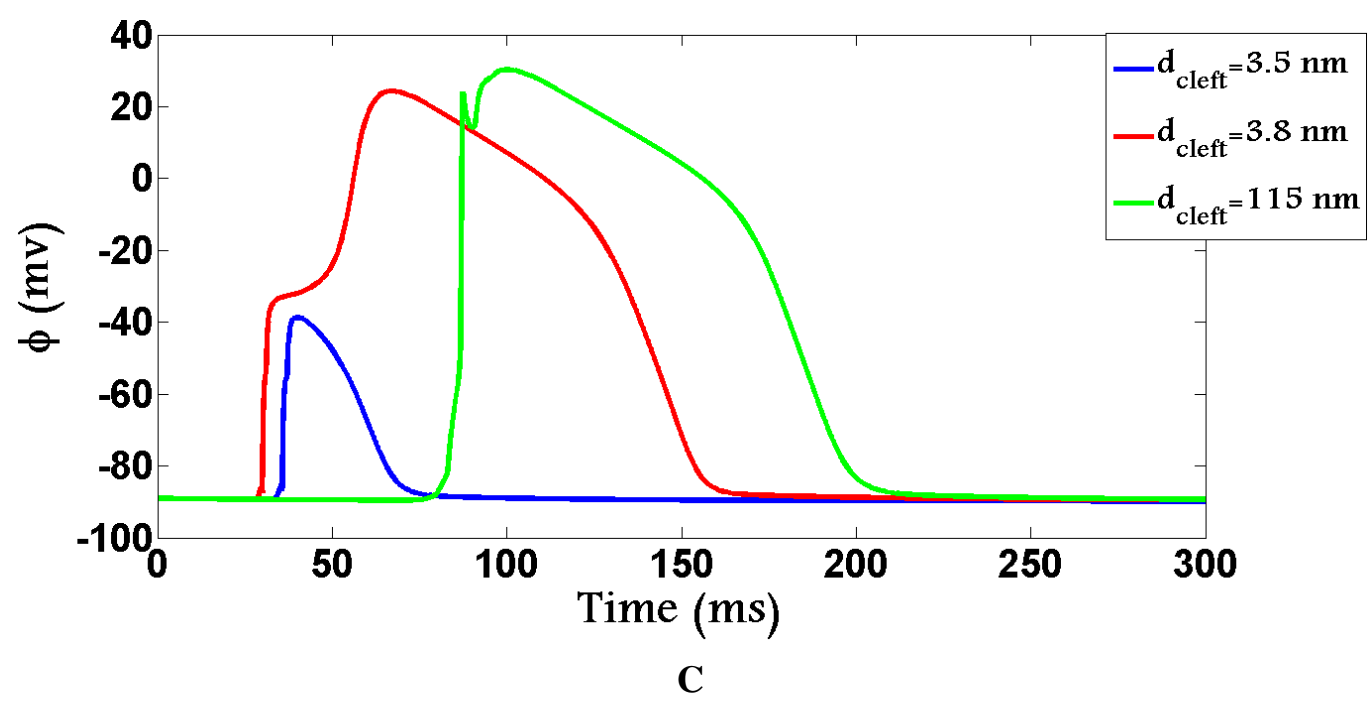

Figure 9 


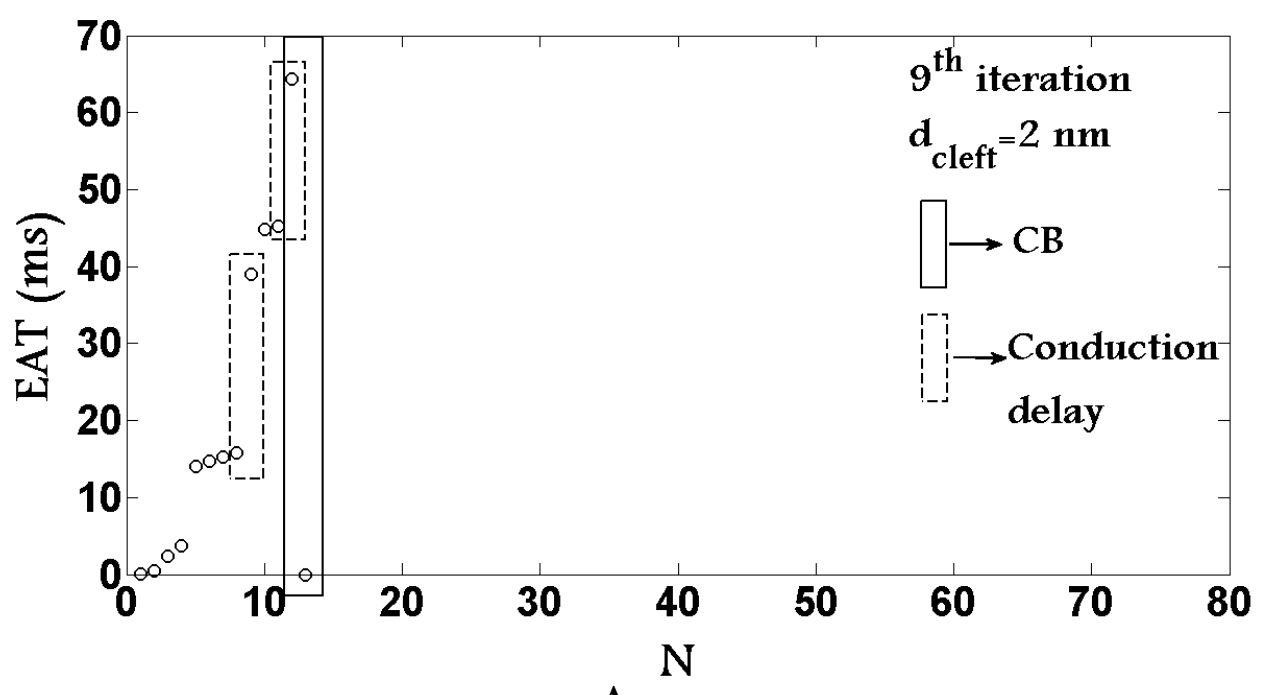

A

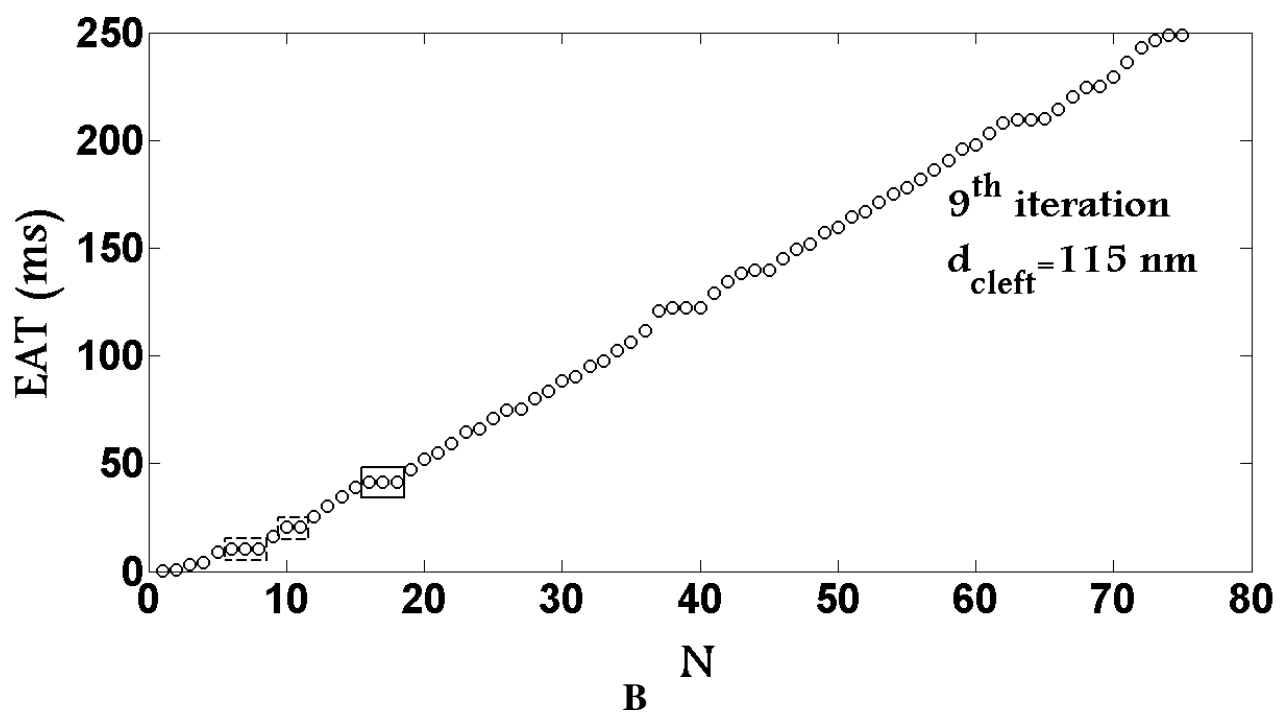

Figure 10 


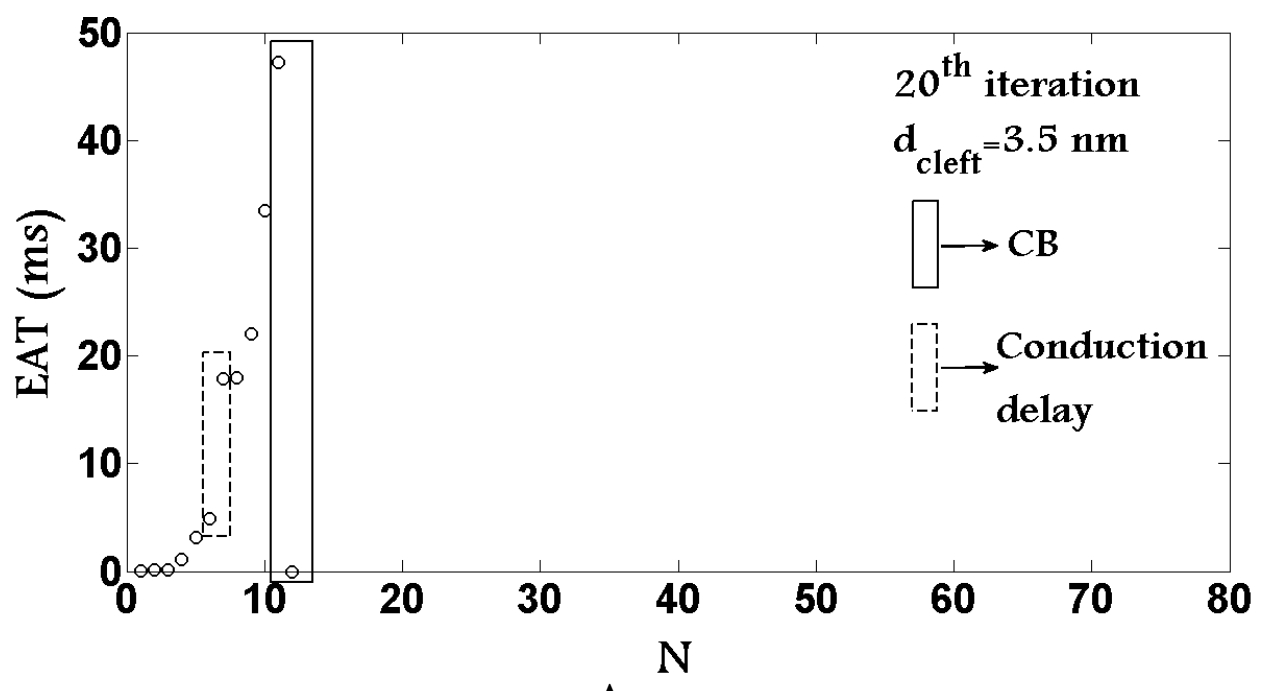

A

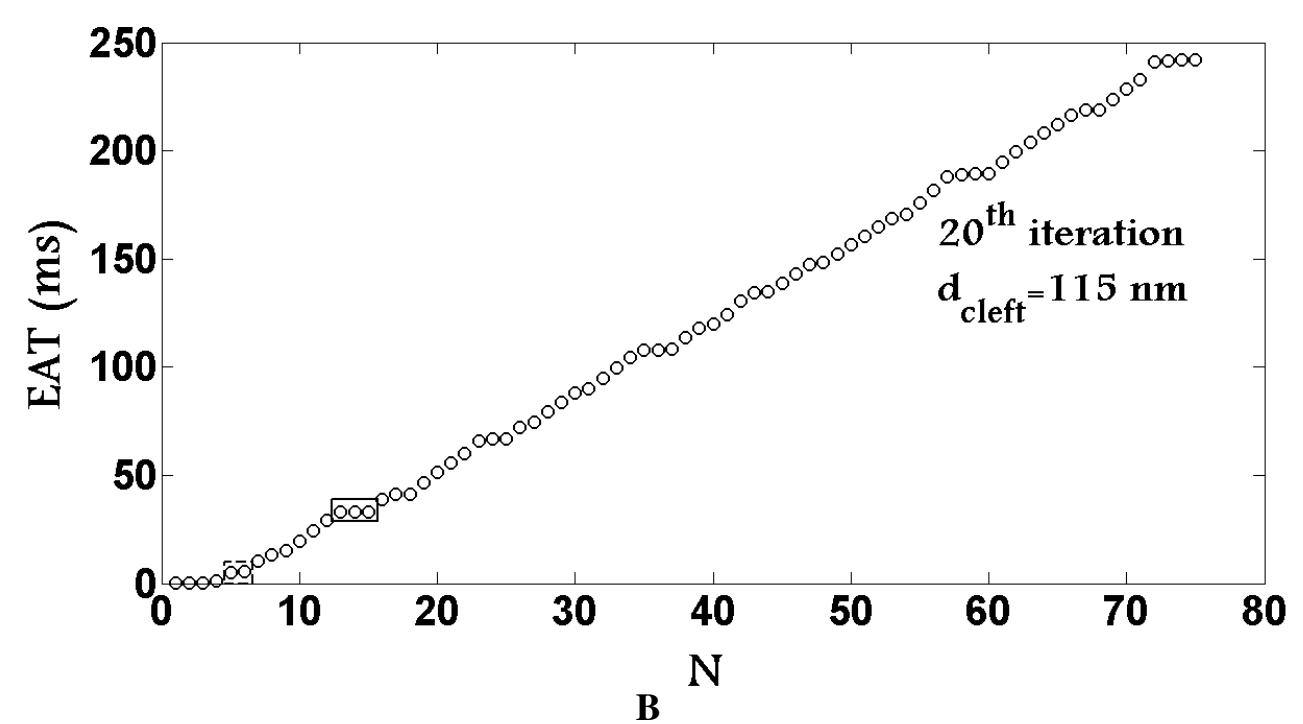

Figure 11 


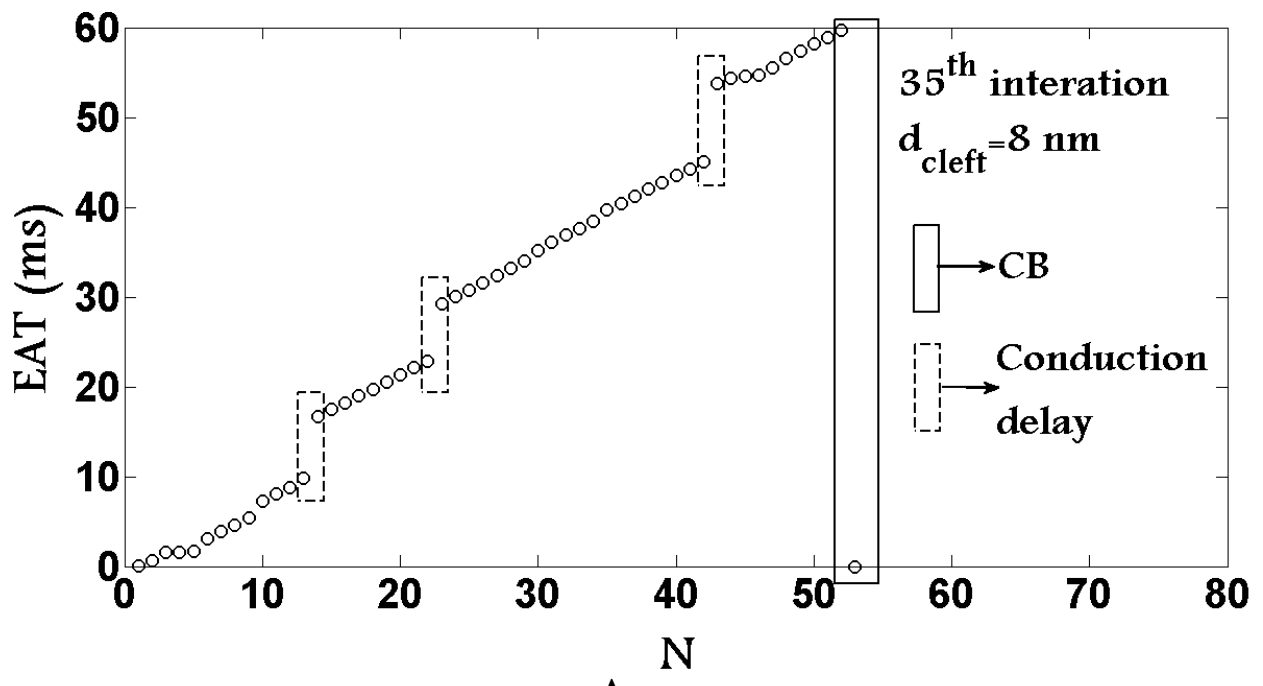

A

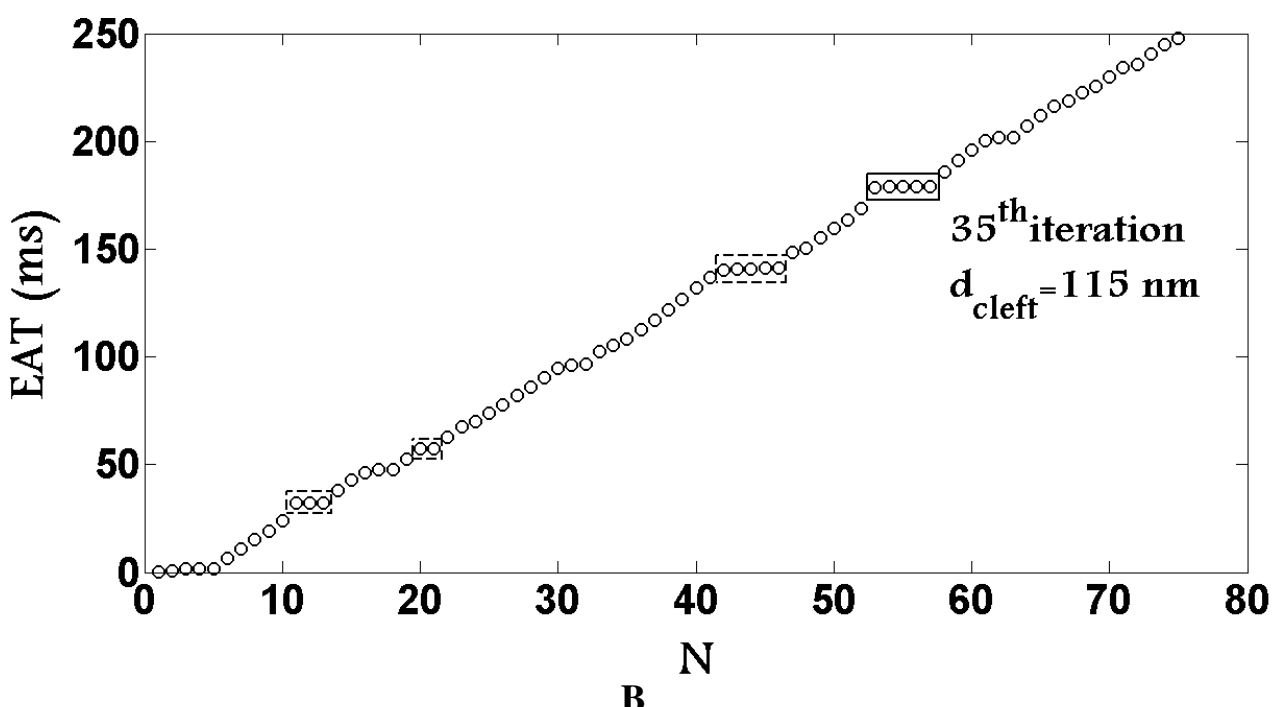

Figure 12 


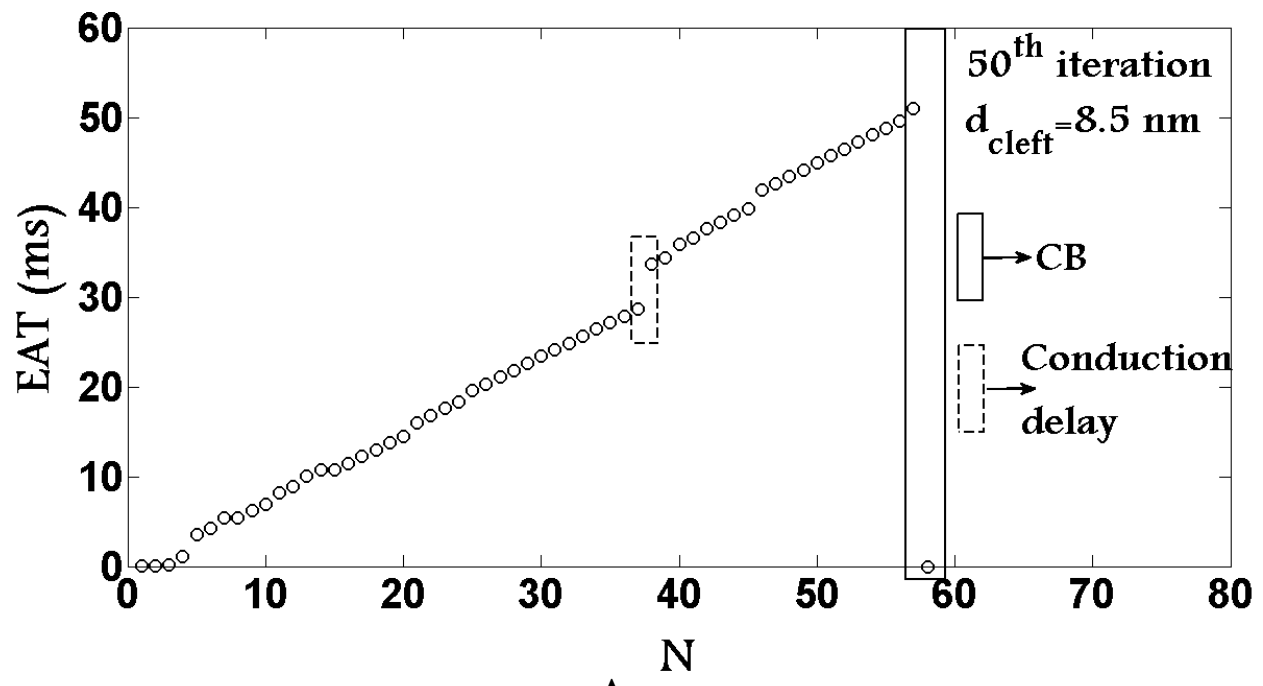

A

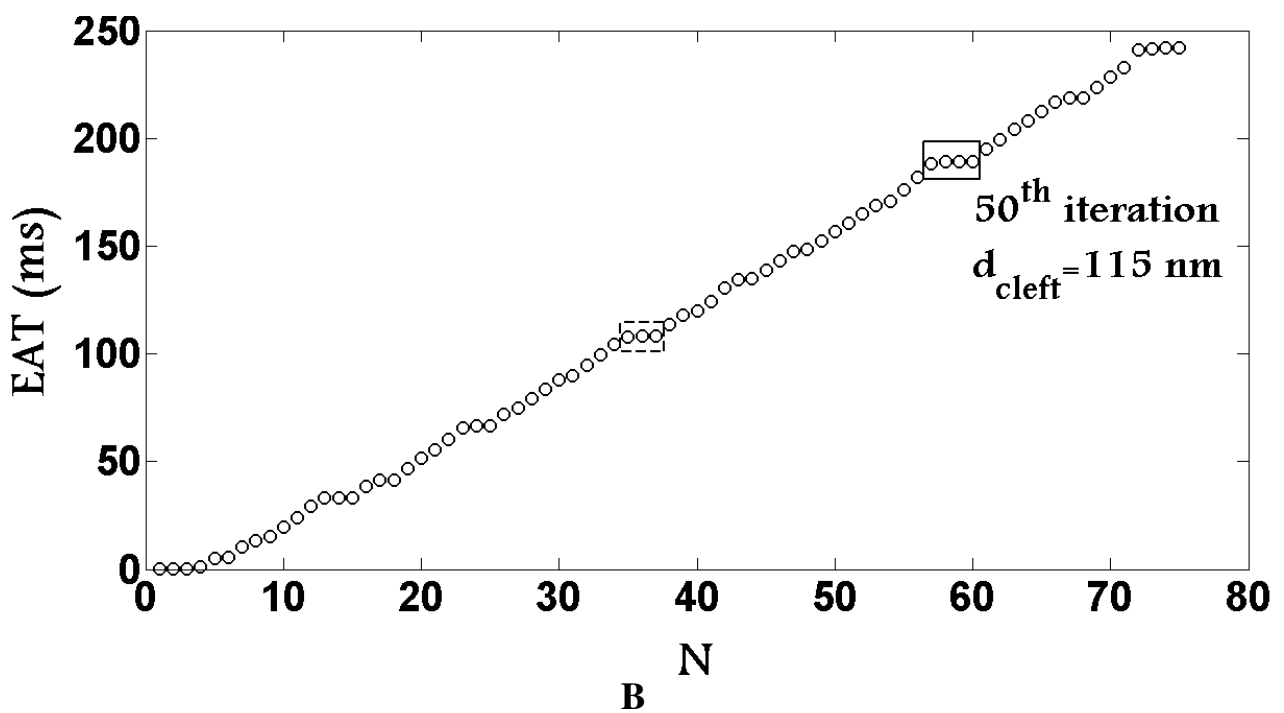

Figure 13 